\title{
Numerical Modeling, Simulation and Evaluation of Conventional and Hybrid Photovoltaic Modules Interconnection Configurations under Partial Shading Conditions
}

\author{
Faisal Saeed a, ${ }^{*}$, Haider Ali Tauqeera, Hasan Erteza Gelani ${ }^{b}$ and Muhammad Hassan Yousuf ${ }^{c}$ \\ a Department of Electrical Engineering, SBASSE, Lahore University of Management Sciences (LUMS), Lahore 54792, Punjab, Pakistan \\ ${ }^{b}$ Department of Electrical Engineering, University of Engineering and Technology Lahore, Faisalabad Campus, Faisalabad, 38000, Punjab, Pakistan \\ ${ }^{c}$ Department of Electrical Engineering, University of Engineering and Technology Lahore, Lahore, 54890, Punjab, Pakistan
}

Corresponding author: Faisal Saeed-19060005@lums.edu.pk

\begin{abstract}
Partial shading on solar photovoltaic (PV) arrays is a prevalent problem in photovoltaic systems that impair the performance of PV modules and is responsible for reduced power output as compared to that in standard irradiance conditions thereby resulting in the appearance of multiple maximas on panel output power characteristics. These maxims contribute to mismatch power losses among PV modules. The mismatch losses depend on shading characteristics together with different interconnected configuration schemes of PV modules. The research presents a comparative analysis of partial shading effects on a $4 \times 4$ PV array system connected in series(S), parallel (P), serries-parallel (SP),total-cross-tied (TCT),central-cross-tied(CCT), bridge-linked(BL), bridge-linked total cross-tied (BLTCT) ,honey-comb(HC), honey-comb total-cross-tied (HCTCT) and ladder (LD) configurations using MATLAB/Simulink. The PV module SPR-X20-250-BLK was used for modeling and simulation analysis. Each module is comprised of 72 number of PV cells and a combination of 16 PV modules was employed for the contextual analysis. Accurate mathematical modeling for the HCTCT configuration under partial shading conditions (PSCs) is provided for the first time and is verified from the simulation. The different configuration schemes were investigated under short-narrow,short-wide,long-narrow,long-wide, diagonal, entire row distribution, and entire column distribution partial shading condition patterns with mathematical implementation and simulation of passing clouds. The performance of array configurations is compared in terms of maximum power generated $\left(P_{m p}\right)$, mismatch power loss $\left(\Delta P_{m l}\right)$, relative power loss $\left(P_{r l}\right)$ and the fill factor $(\mathrm{FF})$. It was inferred that on average, TCT configuration yielded maximum power generation under all shading patterns among all PV modules interconnection configurations with minimum mismatch power losses followed by hybrid and conventional PV array configurations respectively.
\end{abstract}

Keywords: PV array configurations, Partial shading conditions, Performance assessment, Maximum Power Generation, Mismatch power loss, Relative power loss, Fill factor.

\section{Introduction}

In recent years, renewable energy resources (RERs) have gained a peculiar interest to procure cost-effective energy production. RERs have been deployed significantly at a wider scale by several nations to offset electricity generation prices taking into account the fact of ever-increasing energy demand [1-5]. Among RERs, solar generation has gained special attention and remarkable research is headway in the photovoltaic(PV) area [6,7]. According to International Energy Agency (IEA), France report, by the end of 2020 the cumulative global installation capacity of the photovoltaic system is $\mathbf{7 7 5} \boldsymbol{G W}_{\boldsymbol{p}}$ and this could cross $\mathbf{1 0 0 0} \boldsymbol{G W}_{\boldsymbol{p}}$ in 2022 [8]. The primary factor in an exponential deployment of PV systems is the abundant availability of solar insolation in all geographical regions, the efficacy of PV systems to meet energy demands, advancements in power electronics aided hybrid converters, and economic sustainability [9-11].

The solar modules employ the PV effect to generate electrical energy. The performance and efficiency of PV system depend on the solar insolation available to the PV arrays, partial shading (PS) effects, temperature variations, mismatch losses, aging effects and degradation losses [12-14]. However, the variation in solar irradiance and temperature are the key factors that affect the PV energy yield. Under uniform irradiance conditions or standard testing conditions STC $\left(1000 \mathrm{~W} / \mathrm{m}^{2}\right.$ irradiance level and $25^{\circ} \mathrm{C}$ ambient temperature),PV system depicts a unique global maximum power point (GMPP) with nonlinear current-voltage (I-V) and power -voltage (P-V) characteristics as shown in Figure 1.It has been accounted that output power and efficiency of the PV system is significantly reduced due to partial shading effect [15]. Partial shading effects are mainly due to the passing clouds and the existence of trees, poles, towers, and buildings around the PV array[16]. Partial shading contributes to the non-uniform distribution of irradiance over the surface of PV modules interconnected in array or string. This limits the current of the shaded module and subsequently affects the module characteristics connected in series. Therefore bypass diodes are used across the modules to mitigate the effect of mismatch power $\operatorname{losses}\left(\Delta \mathrm{P}_{\mathrm{ml}}\right)$.The impact of partial shading results in the emergence of multiple maximas on output power characteristics of solar modules. Instead of a unique maximum power point, along with GMPP, local maximum power points (LMPP) will also appear on the output power characteristics as shown in Figure 1. Due to partial shading effects, the I-V curve also exhibits multiple maxima and the corresponding fill factor (FF) area is also reduced as shown in Figure 2. The voltage value at the maximum power point $\left(V_{m p}\right)$ from P-V curve aid in computing current value at the maximum power point $\left(I_{m p}\right)$ from I-V curve.Open circuit voltage $\left(V_{o c}\right)$ corresponds to the point where voltage exists the maximum voltage respective to the minimum current value at zero crossings of the axis. Similarly shortcircuit current $\left(I_{s c}\right)$ corresponds to the point where current exhibits maximum value respective to minimum voltage value at zero crossing of the axis. The four parameters; $V_{m p}, I_{m p}, V_{o c}$ and $I_{s c}$ help in determining the maximum power generated $\left(\mathrm{P}_{\mathrm{mp}}\right)$, mismatch power losses $\left(\Delta \mathrm{P}_{\mathrm{ml}}\right)$, relative power losses $\left(\mathrm{P}_{\mathrm{rl}}\right)$, relative power gain $\left(\mathrm{P}_{\mathrm{rg}}\right)$ and the fill factor $(\mathrm{FF})$ of $\mathrm{PV}$ modules interconnection configuration schemes in later sections.

With the passage of time, researches have been in progress to mitigate the effect of mismatch losses that are not entirely due to partial shading conditions (PSCs) but also due to the defect of bypass diodes, soiling and dust over the surface of PV modules, distinct positioning of PV modules in strings and sub-strings with respect to solar insolation, irregularities in physical parameters of PV cell and manufacturing tolerances [17-21]. 


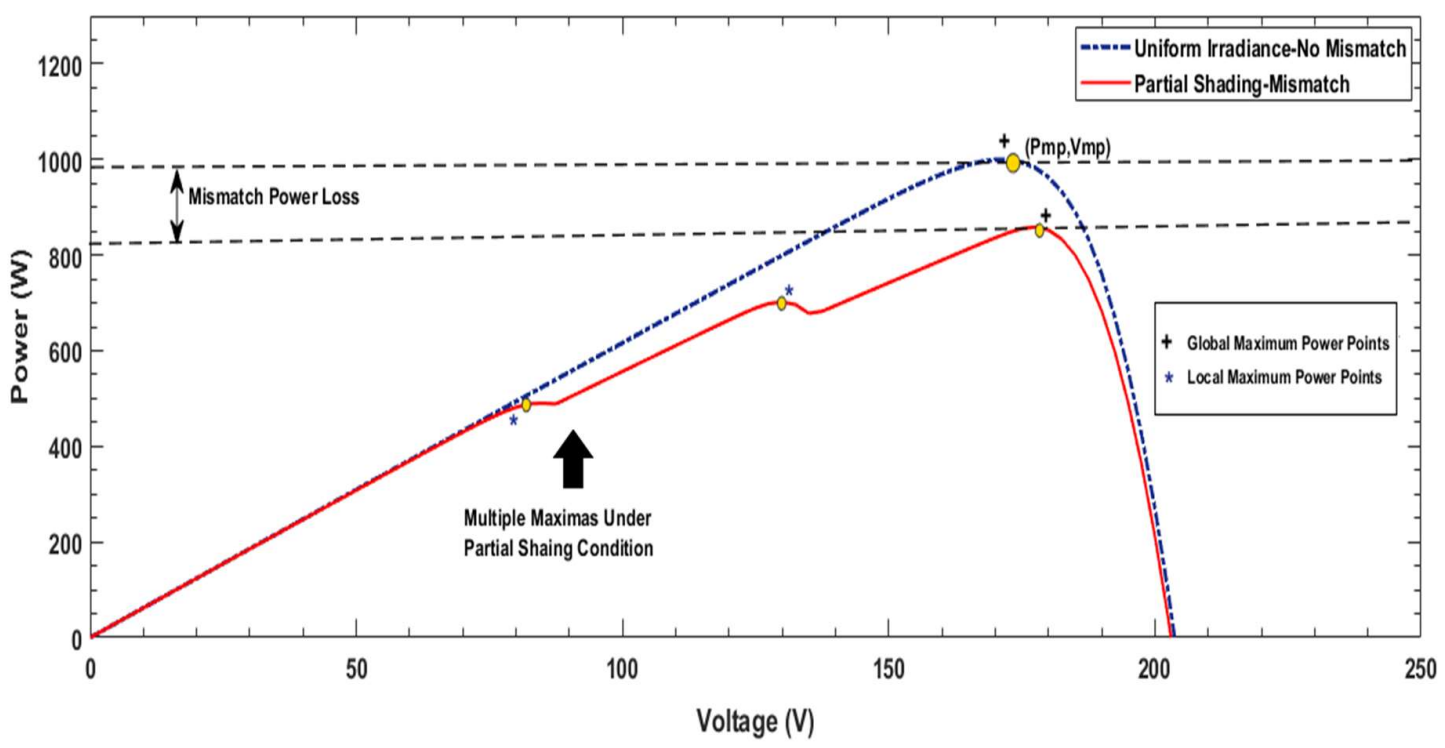

Fig.1. Output power-voltage (P-V) characteristics of photovoltaic modules under STC and partial shading conditions

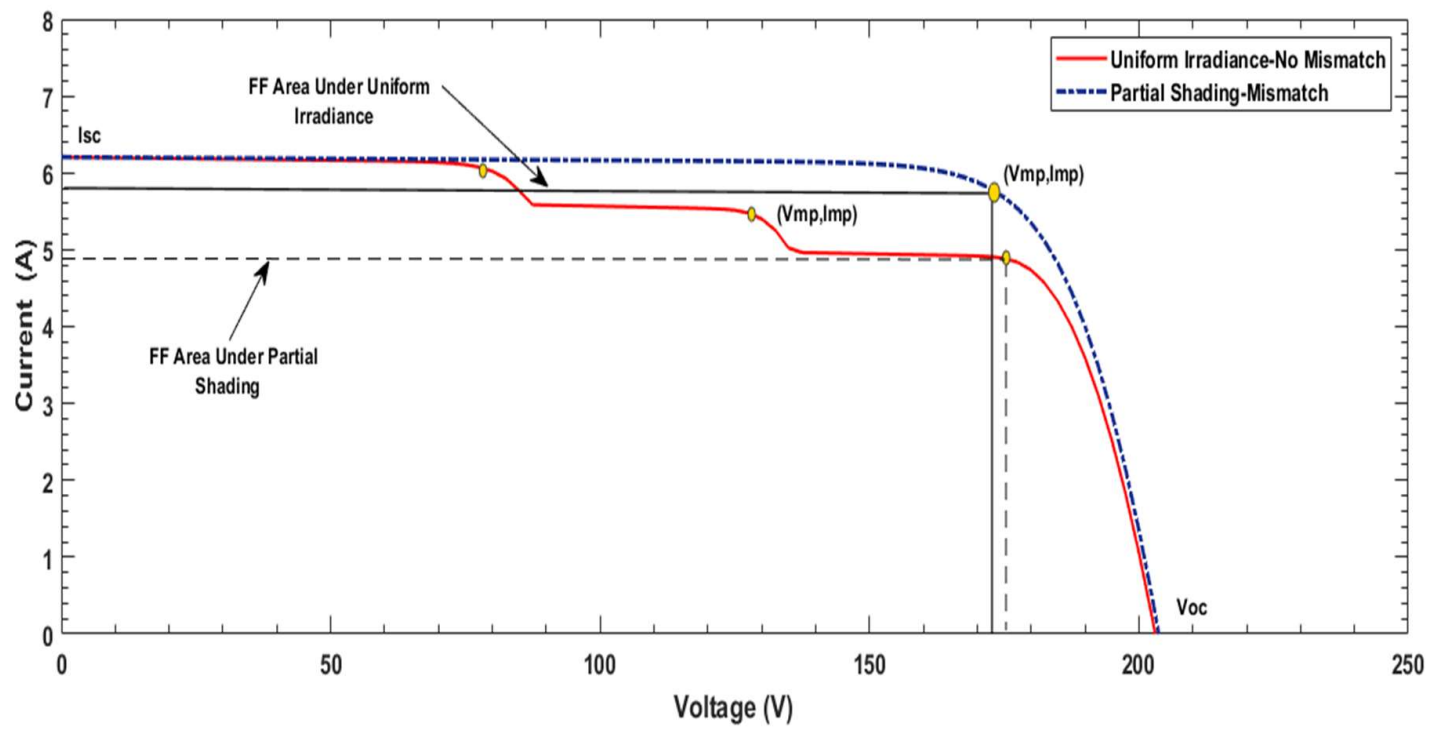

Fig.2. Output current-voltage (P-V) characteristics of photovoltaic modules under STC and partial shading conditions

The mismatch losses can be considerably reduced by employing the subsequent approaches; PV modules interconnection configuration schemes, maximum power point tracking (MPPT) algorithms, system architecture, and converter topologies. However, PV modules interconnection configuration schemes have been accounted as an optimal and cost-effective solution that considerably reduces the effects of mismatch losses due to PSCs [22-25].

\subsection{Comparison of Previous PV array topologies}

A significant literature is being reported on the adoption of various topologies to combat mismatch losses under PSCs. In this section, the prime focus is to provide a comprehensive review of specifically the simulation-based case studies pertaining to the exploration of PV array configurations behavior under PSCs in the past as well as to highlight the novel aspects of current research effort. Alonso-García, et al. [26] detailed a brief comparative analysis of the impact of PSCs on output characteristics of series-connected PV modules with cell variants. The results revealed that a slight increase in shading rate results in higher deformations in I-V characteristics. Performance analysis parameters (PAPs) in the case study were the $\mathrm{V}_{\mathrm{mp}}$ and $\mathrm{I}_{\mathrm{mp}}$. Nguyen and Lehman, [27] proposed a mathematical model to implement passing clouds to generate specific partial shading patterns for different PV array configuration schemes. The model is extendable to any of the PV array configuration schemes. Karatepe, et al. [28] investigated the impact of by-pass diodes for series-parallel (SP), bridge link (BL), and total cross-tied (TCT) PV array topologies under the non-uniform distribution of solar irradiation on solar arrays. TCT configuration depicted superior performance among all configurations in terms of low $\Delta \mathrm{P}_{\mathrm{ml}}$. The case study of Dio et al., [29] on S, P, and series-parallel (SP) PV array configurations under unequal solar radiation inferred that SP configuration 
is the optimal PV configuration design and P PV configuration is not suitable for practical approaches as it draws higher current in the system. PAPs were the GMPP, $\mathrm{V}_{\mathrm{mp}}$ and $\mathrm{I}_{\mathrm{mp}}$. Ramaprabha and Mathur [30] reviewed S, P, SP, TCT, and honeycomb (HC) PV array configurations and PAPs included $\mathrm{P}_{\mathrm{mp}}, \mathrm{V}_{\mathrm{mp}}$ and $\mathrm{I}_{\mathrm{mp}}$. HC PV configuration dominated among all array topologies. Salam and Ramli [31] proposed an electronic circuit alternative of by-pass diodes for PV modules interconnected in S configuration. The performance evaluation parameter was only the efficiency. Belhachat and Larbes [32] comprehensively elaborated modeling and investigation of six different PV array configurations; $\mathrm{S}, \mathrm{P}, \mathrm{SP}, \mathrm{TCT}, \mathrm{BL}$, and HC under seven different shading patterns. PAPs were the $\mathrm{P}_{\mathrm{mp}}, \mathrm{V}_{\mathrm{mp}}, \mathrm{I}_{\mathrm{mp}}$ and $\Delta \mathrm{P}_{\mathrm{ml}}$. TCT PV configuration exhibited superior performance in all shading conditions. Mohammadnejad, et al. [33] proposed a mathematical model for TCT configuration for four different shading condition patterns as well as performed comparative investigation for SP, TCT, BL, and HC PV array configurations. TCT PV array configuration appeared to be the optimal choice in perspective of maximum $\mathrm{P}_{\mathrm{mp}}$ and low $\Delta \mathrm{P}_{\mathrm{ml}}$. Vijayalekshmy, et al.[34] reviewed TCT and Sudoku Puzzle (SuP) PV arrays for mathematically generated six different passing clouds shading patterns and PAPs were the $\Delta \mathrm{P}_{\mathrm{ml}}$ and FF. Pendem and Mikkili [ 35] analyzed the performance of $\mathrm{S}$, SP, and HC PV array schemes. HC PV array topology yielded maximum power followed by SP and S. Bingöl and Özkaya [36] discussed modeling and assessment of $\mathrm{S}, \mathrm{SP}, \mathrm{TCT}, \mathrm{BL}, \mathrm{HC}$ PV modules interconnection configurations considering six PAPs $; \mathrm{P}_{\mathrm{mp}}, \mathrm{V}_{\mathrm{oc}}, \mathrm{I}_{\mathrm{sc}}, \Delta \mathrm{P}_{\mathrm{ml}}$ and the FF. Analysis confirmed TCT PV array configuration to be a better choice under different PSCs. Pendem and Mikkili [37] detailed a comprehensive comparative analysis of conventional PV array configurations; S, P, SP, TCT and hybrid PV array topologies; BL and HC under eight different shading conditions and PAPs; $\mathrm{V}_{\mathrm{oc}}, \mathrm{I}_{\mathrm{sc}}$, GMPP, LMPP, voltage and current values at GMPP and LMPP, FF and the efficiency. Similarly Premkumar, et al [38], Huang et al. [39]; Kreft et al. [40], Reddy and Yammani [41], Wang et al., [42] and Yang et al [43] also provided comprehensive quantitative assessments to reduce $\Delta \mathrm{P}_{\mathrm{ml}}$.

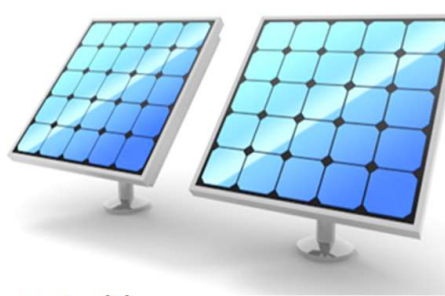

Series $(\mathrm{S})$

Parallel (P)

Series Parallel (SP)

Total Cross Tied (TCT)

Central Cross Tied (CCT)

Bridge Linked (BL)

Bridge Linked Total Cross Tied (BLTCT)

Honey Comb (HCTCT)

Honey Comb Total Cross Tied

Ladder (LD)

PV Array Topologies

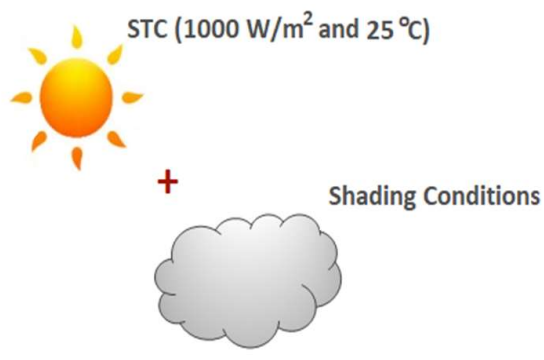

Short Narrow (SN)

Shot Wide (SW)

Long Narrow (LN)

Long Wide (LW)

Diagonal (D)

Entire Row Distribution (ERD)

Entire Column Distribution (ECD)
Performance Assessment Parameters

Open Circuit Voltage (Voc)

Short Circuit Current (Isc)

Voltage at Maximum Power Point (Vmp)

Current at Maximum Power Point (Imp)

Global Maximum Power Point (GMPP)

Local Maximum Power Point (LMPP)

Fill Factor (FF)

Mismatach Power Loss

Relative Power Loss

Fig.3. PV Modules interconnection configuration schemes, shading patterns and performance assessment parameters employed in this case-study

This research effort discusses the modeling,simulation and performance assessment of the $4 \times 4 \mathrm{PV}$ array system connected in series(S), parallel (P), serries-parallel (SP), total-cross-tied(TCT), central-cross-tied(CCT), bridge-linked(BL),honey-comb(HC), honey-comb total-cross-tied (HCTCT) and ladder (LD) configurations under STC and partial shading conditions (PSCs) using MATLAB/Simulink without considering the physical site temperature effects. The assumption of taking fixed temperature for varying incident light intensity is in line with the literature reported studies [2643]. Adoption of a small $4 \times 4 \mathrm{PV}$ array system for simulation investigation is practically feasible according to the studies $[44,45]$ wherein authors detailed both the simulation and practical investigations in this particular contextual analysis. This case study is more comprehensive towards the discussion of PV modules interconnection configurations as compared to the PV array topologies highlighted in the literature to the best of the author's acquaintance. Moreover, accurate mathematical modeling has been performed for HCTCT configuration which depicts one of the novelties of this paper. Simulation implementation of passing clouds to generate shading patterns is also elaborated. The above mentioned PV configuration schemes were investigated in short-narrow(SN), short-wide (SW),long-narrow(LN),long-wide(LW), diagonal(D), entire row distribution (ERD), an entire column distribution (ECD) shading conditions and the comparative performance will be discussed in terms of maximum power generated $\left(\mathrm{P}_{\mathrm{mp}}\right)$, mismatch power losses $\left(\Delta \mathrm{P}_{\mathrm{ml}}\right)$, relative power losses $\left(\mathrm{P}_{\mathrm{rl}}\right)$, relative power gain $\left(\mathrm{P}_{\mathrm{rg}}\right)$ and the fill factor $(\mathrm{FF})$. 
This section discusses an equivalent circuit of a single diode model (SDM) for PV cell and then subsequently discusses the modeling for PV module and array. The equivalent circuit modeling of PV cell, module, and array helps in a basic understanding of output power characteristics.

\subsection{Modeling of a PV Cell Based on SDM}

A PV cell is considered as a current source and the current produced by the PV cell is proportional to the light incident on the cell. An electrical equivalent circuit of a PV cell based on SDM is shown in Figure 4. The photo-generated current is represented by $I_{p g}$ and is proportional to the light falling on the cell. The optical losses of the PV cell are represented by the current source itself and recombination losses are represented by connecting the anti-parallel diode to the current source. The Ohmic losses are denoted by series resistance $\left(R_{s}\right)$ and shunt resistance $\left(R_{p}\right)$.The $R_{s}$ is the resistance offered by PV cell in the path of current flow and $R_{p}$ is leakage resistance of the cell and therefore connected in parallel to the current source.

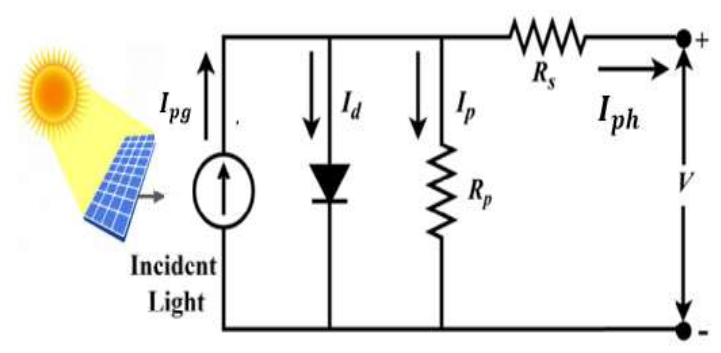

Fig.4. Electrical equivalent circuit model of a photovoltaic cell

Therefore current equation for a PV cell based on SDM can be written as;

$$
I_{p h}=I_{p g}-I_{d}-I_{p}
$$

where $I_{d}$ is the diode current and $I_{p}$ is the shunt current and I-V relation can be expressed as;

$$
I_{p h}=I_{p g}-I_{o}\left(\exp \left(\frac{q\left(V+I_{p h} R_{s}\right)}{n k T}\right)-1\right)-\left(\frac{V+I_{p h} R_{s}}{R_{p}}\right)
$$

Where $q$ is the electron charge and equals $1.602 \times 10^{-19} \mathrm{C}, I_{o}$ the saturation is current of the diode, $n$ is the ideality factor, $k$ is the Boltzmann constant and equals to $1.3806053 \times 10^{-23} \mathrm{~J} / \mathrm{K}$ and $\mathrm{T}$ is the PV cell temperature.

\subsection{Modeling of a PV Module Based on SDM}

The PV module consists of series-connected PV cells and is denoted by $N_{s}$. Considering $I_{p h, m}$ to be module output current, $V_{m}$ to be the module voltage and $N_{s}$ to be the series-connected cells, then the current voltage equation for a PV module based on SDM is expressed as;

$$
I_{p h, m}=I_{p g}-I_{o}\left(\exp \left(\frac{q\left(V+I_{p h, m} N_{s} R_{s}\right)}{N_{s} n k T}\right)-1\right)-\left(\frac{V+I_{p h, m N_{s} R_{s}}}{N_{s} R_{p}}\right)
$$

It is to be noted that for the case of several series-connected PV modules $\left(N_{s m}\right)$ with several connected series cells $\left(N_{s c}\right)$, then $N_{s}$ can be expressed as;

$$
N_{s}=N_{s c} \times N_{s m}
$$

\subsection{Modeling of a PV Array Based on SDM}

PV array is comprised of series and parallel combinations of PV modules. In the present case, consider $N_{s}$ to be the series-connected PV modules and $N_{p}$ to be the parallel combination of modules to form a PV string, $I_{p h, a}$ to be the array output current and $V_{a}$ to be the array output voltage, then $\mathrm{I}-\mathrm{V}$ relation can be written as equation as;

$$
I_{p h, a}=I_{p g}-I_{o}\left(\exp \left(\frac{q\left(V+I_{p h, a}\left(\frac{N_{s}}{N_{p}}\right) R_{s}\right)}{N_{s} n k T}\right)-1\right)-\left(\frac{V+I_{p h, a}\left(\frac{N_{s}}{N_{p}}\right) R_{s}}{N_{s} R_{p}}\right)
$$

It is important to mention here that MATLAB/Simulink modeling of PV arrays is performed based on Equation (5). The PV module SPR-X20-250BLK is being used for the modeling and simulation analysis of $4 \times 4$ PV modules inter-connection configuration. Each module is comprised of 72 
number of PV cells and a sum number of 16 PV modules are being employed for the simulation analysis. The module detail parameters are enlisted in Table 1.

Table 1

Parameters of SPR-X20-250-BLK PV Module at STC $\left(1000 \mathrm{~W} / \mathrm{m}^{2}\right.$ and $\left.25^{\circ} \mathrm{C}\right)$

\begin{tabular}{ccc}
\hline S.No & Parameters & Values \\
\hline 1 & Maximum power, $P_{\max }$ & $249.952 \mathrm{~W}$ \\
2 & Voltage at maximum power, $V_{m p}$ & $42.8 \mathrm{~V}$ \\
3 & Current at maximum power, $V_{m p}$ & $5.84 \mathrm{~A}$ \\
4 & Open circuit voltage, $V_{o c}$ & $50.93 \mathrm{~V}$ \\
5 & Short circuit current, $I_{s c}$ & $6.2 \mathrm{~A}$ \\
6 & Temperature co-efficient of open circuit voltage, & -0.35602 \\
& $\left(\% /{ }^{\circ} \mathrm{C}\right)$ & 0.07 \\
7 & Temperature co-efficient of short circuit current, \\
& $\left(\% /{ }^{\circ} \mathrm{C}\right)$ & 72 \\
8 & Number of cells per module, $\mathrm{ns}$ & $0.301 \Omega$ \\
9 & Series resistance, $R_{s}$ & $621.2034 \Omega$ \\
10 & Shunt resistance, $R_{p}$ & 1.1367 \\
11 & Diode ideality factor, $\mathrm{n}$ & 61.4 in $\times 31.4 \mathrm{in}$ \\
12 & Dimensions of the PV module $(=\mathrm{Area})$ & Mono- \\
13 & Module technology & Crystalline \\
\hline
\end{tabular}

\section{Performance Assessment Parameters}

This section provides a brief overview of the performance evaluation parameters that have been taken into account for PV array topologies under STC or uniform irradiation conditions and PSCs in later sections. The focus of the study is to investigate the key parameters that can comprehensively differentiate the performance of PV arrays under PSCs to have an idea of optimal PV array topology that yields more energy output under particular shading conditions and are discussed here.

\subsection{Power Generated at Maximum PowerPoint}

The maximum power that can be extracted from PV cell, module, or array is termed as power generated at maximum power point denoted by $P_{m p}$ . It equals the global maximum power point (GMPP) of the module non-linear P-V curve. Alternatively, it can be obtained from the product of voltage at the maximum power point and current at the maximum power point. $P_{m p}$ can be mathematically expressed as;

$$
P_{m p}=V_{m p} \times I_{m p} \quad(\mathrm{~W})
$$

\subsection{Mismatch Power Loss}

It equals the difference of the power generated at the maximum power point at STC to the peak power generated under PSC divided by maximum power generated under uniform irradiance conditions. Mismatch power loss is denoted as $\Delta \mathrm{P}_{\mathrm{ml}}$ and is expressed in percentage. Under PSC, $P_{m p}$ corresponds to the GMPP among global maximum power point and local maximum power points. Mismatch power loss mathematical can be given as;

$$
\Delta P_{m l}=\frac{P_{m p, S T C}-P_{m p, P S C}}{P_{m p, S T C}}(\%)
$$

\subsection{Relative Power Loss}

In order to compute relative power $\operatorname{loss}\left(P_{r l}\right)$, theoretical power yield $\left(P_{t y}\right)$ evaluation is an earlier step in the calculation of $P_{r l}$ for a particular PV array topology under specific PSCs. $P_{t y}$ can be computed using Equation (8) in which $\mathrm{S}$ is the solar irradiation of the individual module under particular partial shading condition, $S_{o}$ is the solar irradiation under STC, $i$ indicates the respective PV module and $N$ is the total number of modules in a PV array system.

$$
P_{t y}=\sum_{i=1}^{N}\left(\frac{s}{s_{o}} \times P_{m p, i}\right) \quad(\mathrm{W})
$$

Now the relative power loss of a certain PV array topology under partial PSC can be expressed as;

$$
P_{r l}=P_{t y}-P_{m p, P S C} \quad \text { (W) }
$$

3.4 Fill Factor 
Fill factor $(\mathrm{FF})$ is the ratio of the maximum power $\left(P_{m p}\right)$ that can be extracted from a PV cell, module, or array to the ideal achievable power $\left(V_{o c} \times I_{s c}\right)$, expressed in percentage and is given as;

$$
F F=\frac{P_{m p}}{\left(V_{o c} \times I_{s c}\right)}=\frac{V_{m p} \times I_{m p}}{\left(V_{o c} \times I_{s c}\right)}
$$

\section{$4 \quad$ PV Modules Interconnection Configuration Schemes and the Shading Patterns}

This section discusses the different PV array topologies and the shading patterns that have been considered for the case study. The PV modules are connected in S, P, SP, TCT, CCT, BL, BLTCT, HC, LD configurations, and in the proposed HCTCT topology. Also, the PV array configurations are evaluated under short-narrow (SN), short wide (SW), long-narrow (LN), long wide (LW), diagonal (D), entire row distribution (ERD), and entire column distribution (ECD) shading conditions. Further insight regarding array configurations and shading conditions is a provider in the subsection discussed here.

\subsection{PV Modules Interconnection Configuration Schemes}

\subsubsection{Series (S) PV Array Configuration}

In series (S) PV array configuration, the PV modules are interconnected in a way to extract the maximum cumulative voltage of PV modules while having the same current value as the output put current of the array configuration as that of an individual module. The $4 \times 4$ series PV array topology is shown in Figure 5 (a). Under PSCs, the mismatch losses due to the emergence of GMPP and LMPP are mitigated by employing bypass diodes and blocking diodes. Further insight regarding the use of bypass diodes is provided in section 5 .

\subsubsection{Parallel (P) PV Array Configuration}

In parallel (P) PV array configuration, the PV modules are interconnected in a way to extract the maximum cumulative current of PV modules while having the same voltage value as the output voltage of the array configuration as that of individual module voltage. The $4 \times 4$ series PV array topology is shown in Figure 5 (b). It has been accounted that parallel PV modules interconnection configuration scheme is lesser prone to mismatch losses and relative power losses as compared to S PV array configuration and this will be more clear in later sections discussing the detailed simulation analysis of PV array topologies.

\subsubsection{Series-Parallel (SP) PV Array Configuration}

The PV modules are first interconnected in a series configuration to acquire the desired output voltage to form a PV string and subsequently interconnected in parallel fashion to have the desired output current. The $4 \times 4$ series-parallel (SP) PV array topology is shown in Figure 5 (c). The SP PV array configuration is the most commonly used PV array topology because of its additional pros over other technologies such as ease to manufacture, economical and redundant connections.

\subsubsection{Total Cross Tied (TCT) PV Array Configuration}

In total cross-tied (TCT) configuration, PV modules are connected in a way so that voltage across each row is equal to the $V_{o c}$ of a single module and $\mathrm{PV}$ array voltage is the cumulative voltage of each row. The output current of the PV array is the cumulative current of all the PV modules interconnected in a row. The $4 \times 4$ total cross-tied (TCT) PV array topology is shown in Figure 5 (d). As it can be observed from the figure that TCT configuration employs more number of electrical connections and thus its architecture is a bit complex as compared to other PV array topologies.

\subsubsection{Central Cross Tied (CCT) PV Array Configuration}

The central cross-tied (CCT) configuration is similar to SP array configuration and is distinguished as CCT array configuration has electrical connections in the middle row of the SP PV array topology. In this way, CCT inherently takes the advantage of SP and TCT configurations as CCT array topology has a lesser number of PV modules connection in series as that of SP configuration and less number of electrical connections as in TCT. The $4 \times 4$ central cross-tied (TCT) PV array topology is shown in Figure 5 (e).

\subsubsection{Bridge Linked (BL) PV Array Configuration}

Bridge linked (BL) PV array configuration utilizes less number of series-connected modules as compared to S and SP configurations and the The PV modules are first interconnected in a series configuration and then in parallel to achieve the desired output voltage and current characteristics. The $4 \times 4$ bridge linked (BL) PV array topology is shown in Figure 5 (f).

\subsubsection{Bridge Linked Total Cross Tied (BLTCT) PV Array Configuration}

The bridge-linked total cross-tied (BLTCT) configuration is similar to the BL PV array configuration with the exception that in BLTCT configuration is cross-tied from the middle of the row.BLTCT utilizes less number of series-connected modules as compared to BL and has a lesser number of electrical connections than TCT. BLTCT is a hybrid configuration as it is a combination of BL PV array topology and CCT array configuration. The $4 \times 4$ bridge linked total cross-tied (BLTCT) PV array topology is shown in Figure 5 (g). 

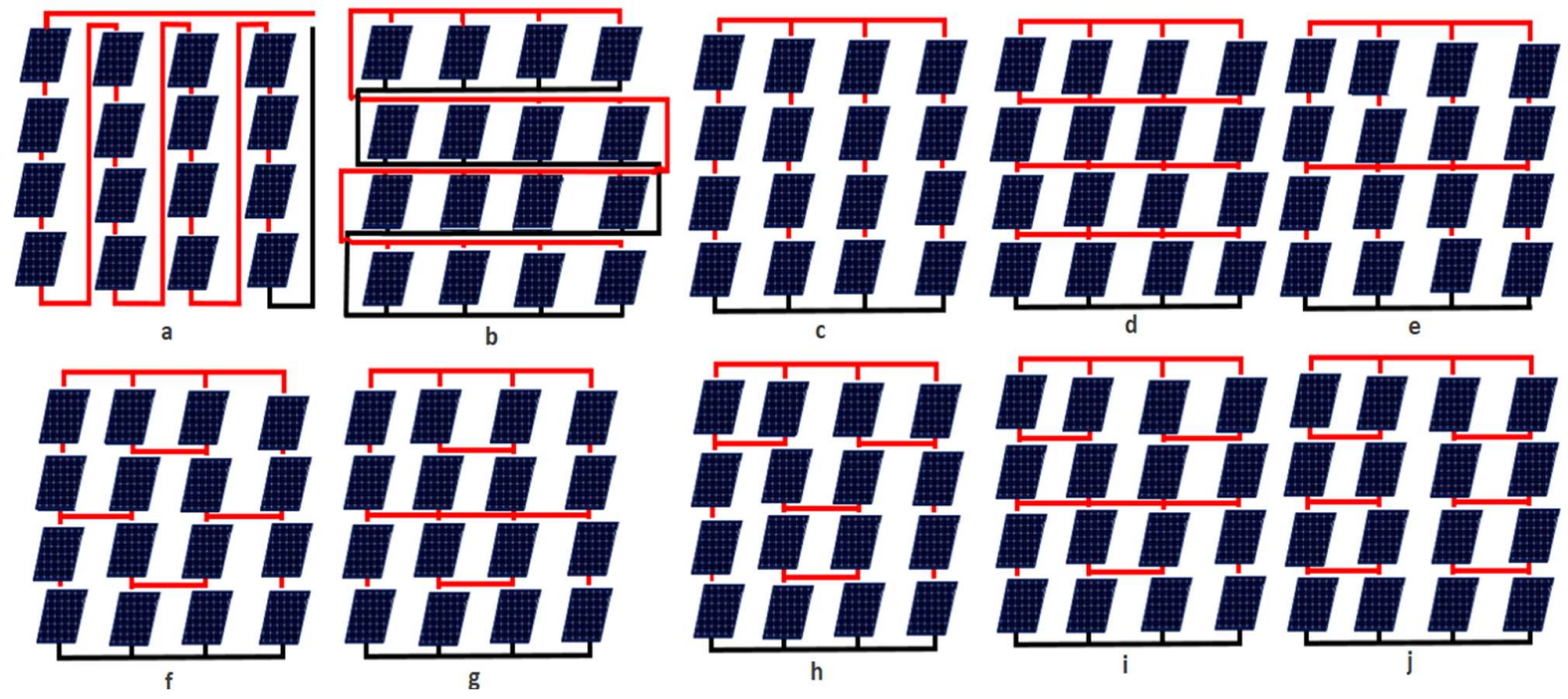

Fig.5. PV modules interconnection configuration schemes schematics; (a)S (b) P (c) SP (d) TCT (e )CCT (f) BL (g) BLTCT (h) HC (i) HCTCT (j) LD

\subsubsection{Honey Comb (HC) PV Array Configuration}

The honeycomb (HC) PV array configuration utilizes less number of series-connected PV modules as compared to S and SP array topologies and a high number of PV modules connected in series than TCT configuration. So HC PV array configuration has overcome the drawbacks that a user face in S, P, SP, and BL configurations. HC PC array topology architecture is similar to the hexagon structure of a honeycomb. The $4 \times 4 \mathrm{Honeycomb}$ (HC) PV array topology is shown in Figure 5 (h).

\subsubsection{Honey Comb Total Cross Tied (HCTCT) PV Array Configuration}

The honeycomb total cross-tied (HCTCT) PV array configuration is similar to HC PV array topology except it is cross-tied from the middle rows of the HC configuration. HCTCT array topology utilizes less number of series-connected PV modules to that of S and SP configurations and the higher number of series connections than BL, BLTCT, and HC PV array configurations. The $4 \times 4$ Honeycomb total cross-tied (HCTCT) PV array topology is shown in Figure 5 (i). The detailed mathematical modeling for HCTCT configuration taking into account the effects of PSCs has been done and will be discussed in section 5 .

\subsubsection{Ladder (LD) PV Array Configuration}

In ladder(LD) PV array configuration the PV modules are connected in SP array configuration and then one of the consecutive columns have has an entire series-connected PV modules row and has an architecture similar to that of a ladder.LD array configuration has a lesser number of modules connected in series as compared to that of TCT. The $4 \times 4$ ladder (LD) PV array topology is shown in Figure 5 (j).

\subsection{Mathematical Modeling of Passing Clouds and Partial Shading Patterns}

The PV modules are subjected to various partial shading conditions to have a comprehensive performance assessment of the PV array topologies. The PV modules are partially shaded by the passing clouds to obtain partial shading variants. The shadow of the passing clouds results in nonuniform distribution of solar insolation over the PV modules. For this particular case study, solar irradiance is varied from $1000 \mathrm{~W} / \mathrm{m}^{2}$ to $900 \mathrm{~W} / \mathrm{m}^{2}, 700 \mathrm{~W} / \mathrm{m}^{2}, 500 \mathrm{~W} / \mathrm{m}^{2}$ and $300 \mathrm{~W} / \mathrm{m}^{2}$. The change in solar irradiance level due to passing clouds from STC conditions changes the $V_{o c}$ and $I_{s c}$ of each PV cell and the PV module.

To have mathematical modeling and simulation of passing clouds a method has been proposed in [8]. The partial shading methods employed for this case-study include short narrow (SN), short wide (SW), long-narrow (LN), long wide (LW), diagonal (D), entire row distribution (ERD) and entire column distribution (ECD) partial shading patterns. Further details regarding each shading pattern are discussed later in this section. The distance $R_{j, k}$ between the PV modules with index $(\mathrm{j}, \mathrm{k})$ at instant of time $t_{c}$ and the center of cloud is determined by solving Equation 11.

$$
R_{j, k}=\sqrt{\left(j-t_{c} \times v\right)^{2}+\left(k-t_{c} \times v\right)}
$$


The cloud is moving with speed $v$ and the realistic values for the ratio of solar irradiance for each PV module range from 0 to 1 and can be specified using the sine function as given in subsequent equation wherein $I_{s c, o}$ is the short-circuit current of the unshaded PV cell and $I_{s c(j, k)}$ is the short-circuit current of the module at position $(j, k)$.

$$
\frac{I_{s c(j, k)}}{I_{s c, o}}=0.5+\frac{\sin \left(R_{j, k}\right)}{1+R_{j, k}}
$$

The short circuit current of the PV cell is approximately proportional to the available solar insolation. Therefore, the effect of passing cloud to the PV modules interconnection configuration schemes may be modeled as the change of short circuit current all PV strings. The implementation of passing clouds according to a particular shading pattern is illustrated in Figure 6.

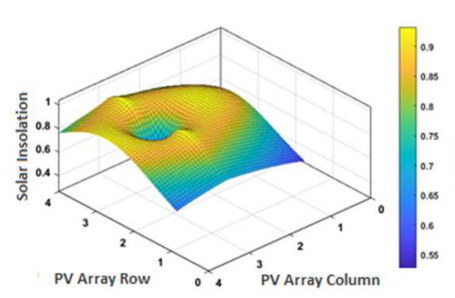

a

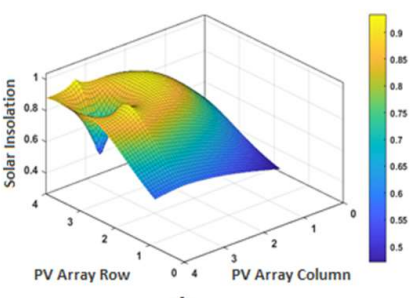

b

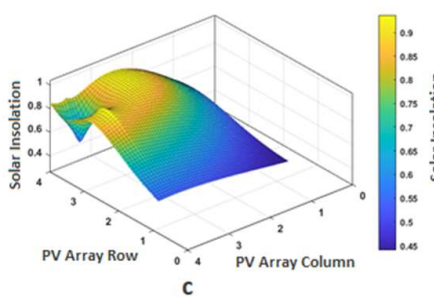

c

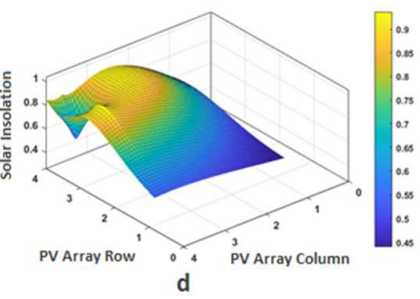

d

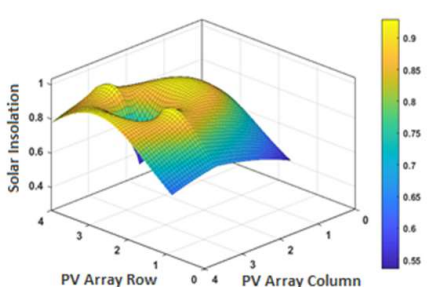

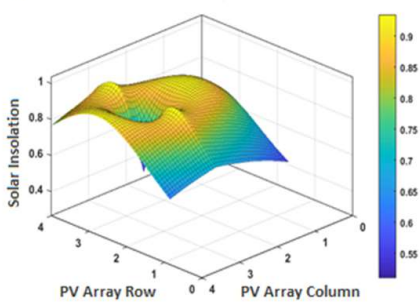

f

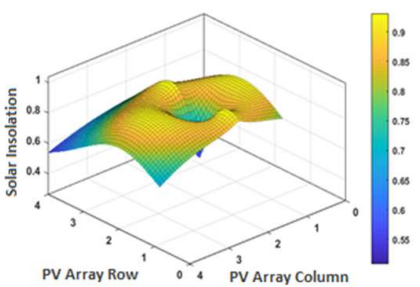

g

Fig.6. Partial shading patterns (a) short narrow (SN) (b) short wide (SW) (c) long narrow (LN) (d) long wide (LW) (e) diagonal (D) (f) entire row distribution (ERD) (g) entire column distribution (ECD)

To provide further insight on a particular shading pattern corresponding to the passing clouds to generate specific shading condition, PV modules have been placed in $4 \times 4$ arrangement and for ease, a matrix form pattern is taken into account as given by Equation 13 to have the exact location of the module and the shading patterns wherein $M_{j k}$ denotes module (M) location in the specific row (j) and column (k). Figure 7 (a) illustrates the solar insolation levels being employed and PV module's location. The detailed characteristics of all shading patterns are illustrated in Figure 7 (b)

$$
M_{j k}=\left[\begin{array}{ccc}
M_{11} & \cdots & M_{1 k} \\
\vdots & \ddots & \vdots \\
M_{j 1} & \cdots & M_{j k}
\end{array}\right]
$$

where

$j=1,2,3,4$ and $k=1,2,3,4$

\subsubsection{Short-Narrow (SN) Shading Pattern}

Short narrow (SN) shading condition has been named so as PSC effects will appear so that shaded modules length is short compared to the length of the PV string and is narrow compared to the width of the PV string.SN shading condition has been shown in Figure 7(b). In this case the module at the place of $M_{11}$ is subjected to an irradiation level of $300 \mathrm{~W} / \mathrm{m}^{2}$ and module at $M_{21}$ will receive $500 \mathrm{~W} / \mathrm{m}^{2}$ of radiation while the rest of the modules placed at $M_{12}, M_{13}, M_{14}, M_{22}, M_{23}, M_{24}, M_{31}, M_{32}, M_{33}, M_{34}, M_{41}, M_{41}, M_{42}, M_{43}$ and $M_{44}$ positions will receive uniform irradiance or the irradiance at STC.

\subsubsection{Short-Wide (SW) Shading Pattern}

Short-wide (SW) shading condition has been named so as PSC effects will appear so that shaded modules length is short compared to PV array length and wide compared to the width of the PV string. In this case the modules at the

place of $M_{11}, M_{12}$ are subjected to irradiation level of $\quad 300 \mathrm{~W} / \mathrm{m}^{2}$ and modules at $M_{21}, M_{22}$ will receive $500 \mathrm{~W} / \mathrm{m}^{2}$ of solar irradiation while the rest of the modules placed at $M_{13}, M_{14}, M_{23}, M_{24}, M_{31}, M_{32}, M_{33}, M_{34}, M_{41}, M_{42}, M_{43}$ and $M_{44}$ positions will receive uniform solar insolation or the irradiance at STC.SW shading condition pattern has been shown in Figure $7(\mathrm{~b})$

$$
\text { Long Narrow (LN) Shading Condition Pattern }
$$

Long narrow (LN) shading condition has been named so as PSC effects will appear so that shaded modules length is long compared to PV string and narrow compared to the width of the PV array. In this case the modules at the place of $M_{11}, M_{12}, M_{21}$ are subjected to irradiation level of 300 $\mathrm{W} / \mathrm{m}^{2}$ and modules at $M_{22}, M_{31}, M_{32}$ will receive $500 \mathrm{~W} / \mathrm{m}^{2}$ of solar irradiation, $M_{41}, M_{42}$ are subjected to solar insolation of $700 \mathrm{~W} / \mathrm{m}^{2}$ while the rest of the modules placed at $M_{13}, M_{14}, M_{23}, M_{24}, M_{33}, M_{34}, M_{43}$ and $M_{44}$ positions will receive uniform solar insolation or the irradiance at STC.LN shading condition pattern has been shown in Figure 7 (b). 


\subsubsection{Long Wide (LW) Shading Pattern}

Long narrow (LW) shading condition has been named so as PSC effects will appear so that shaded modules length is long compared to PV string and wide compared to the width of the PV array. In this case the modules at the place of $M_{11}, M_{12}, M_{21}, M_{22}$ are subjected to irradiation level of $300 \mathrm{~W} / \mathrm{m}^{2}$ and modules at $M_{13}, M_{23}, M_{33}$ will receive $500 \mathrm{~W} / \mathrm{m}^{2}$ of solar irradiation, $M_{41}, M_{42}$ are subjected to solar insolation of $700 \mathrm{~W} / \mathrm{m}^{2}, M_{43}$ is subjected to solar insolation of $900 \mathrm{~W} / \mathrm{m}^{2}$ while the rest of the modules placed

uniform solar insolation or the irradiance at STC.D shading condition pattern has been shown in Figure 7(b).

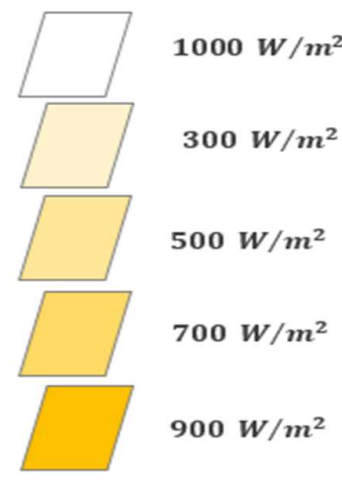

\begin{tabular}{|c|c|c|c|}
\multicolumn{4}{|c}{ SN Shading Pattern } \\
\hline 300 & 1000 & 1000 & 1000 \\
\hline 500 & 1000 & 1000 & 1000 \\
\hline 1000 & 1000 & 1000 & 1000 \\
\hline 1000 & 1000 & 1000 & 1000 \\
\hline
\end{tabular}

\begin{tabular}{|l|l|l|l|}
\hline $\mathbf{M}_{11}$ & $\mathbf{M}_{12}$ & $\mathbf{M}_{13}$ & $\mathbf{M}_{14}$ \\
\hline $\mathbf{M}_{21}$ & $\mathbf{M}_{22}$ & $\mathbf{M}_{23}$ & $\mathbf{M}_{24}$ \\
\hline $\mathbf{M}_{31}$ & $\mathbf{M}_{32}$ & $\mathbf{M}_{33}$ & $\mathbf{M}_{34}$ \\
\hline $\mathbf{M}_{41}$ & $\mathbf{M}_{42}$ & $\mathbf{M}_{43}$ & $\mathbf{M}_{44}$ \\
\hline
\end{tabular}

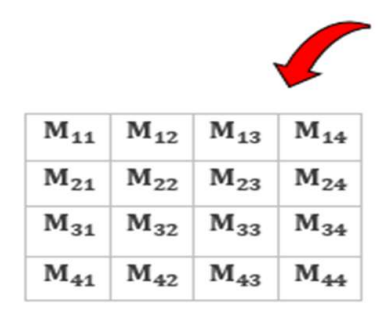

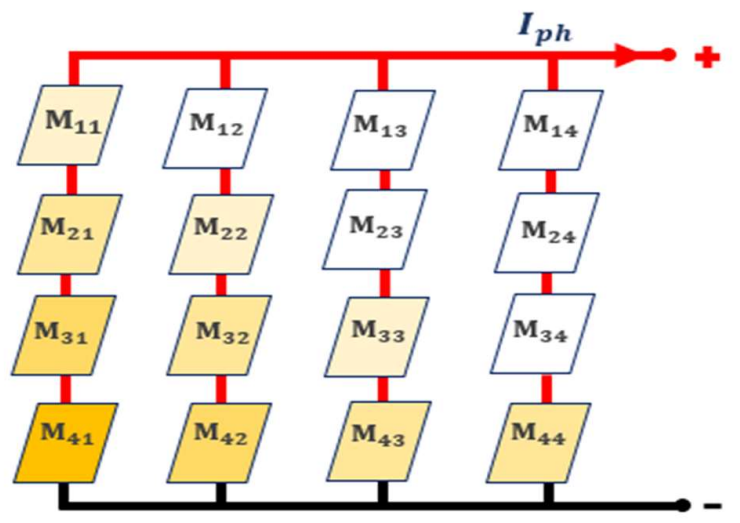

a

\begin{tabular}{|l|l|l|l||c|c|c|c|}
\multicolumn{4}{|c}{ LN Shading Pattern } & \multicolumn{4}{c}{ LW Shading Pattern } \\
\hline $\mathbf{3 0 0}$ & $\mathbf{3 0 0}$ & $\mathbf{1 0 0 0}$ & $\mathbf{1 0 0 0}$ & $\mathbf{3 0 0}$ & $\mathbf{3 0 0}$ & $\mathbf{5 0 0}$ & $\mathbf{1 0 0 0}$ \\
\hline $\mathbf{3 0 0}$ & $\mathbf{5 0 0}$ & $\mathbf{1 0 0 0}$ & $\mathbf{1 0 0 0}$ & $\mathbf{3 0 0}$ & $\mathbf{3 0 0}$ & $\mathbf{5 0 0}$ & $\mathbf{1 0 0 0}$ \\
\hline $\mathbf{5 0 0}$ & $\mathbf{5 0 0}$ & $\mathbf{1 0 0 0}$ & $\mathbf{1 0 0 0}$ & $\mathbf{3 0 0}$ & $\mathbf{3 0 0}$ & $\mathbf{5 0 0}$ & 1000 \\
\hline $\mathbf{7 0 0}$ & $\mathbf{7 0 0}$ & $\mathbf{1 0 0 0}$ & $\mathbf{1 0 0 0}$ & $\mathbf{7 0 0}$ & $\mathbf{7 0 0}$ & $\mathbf{9 0 0}$ & 1000 \\
\hline
\end{tabular}

\begin{tabular}{|c|c|c|c|}
\hline \multicolumn{4}{|c|}{ D Shading Pattern } \\
\hline 300 & 1000 & 1000 & 1000 \\
\hline 1000 & 500 & 1000 & 1000 \\
\hline 1000 & 1000 & 700 & 1000 \\
\hline 1000 & 1000 & 1000 & 900 \\
\hline
\end{tabular}

ERD Shading Pattern

\begin{tabular}{|c|c|c|c|}
\hline 300 & 500 & 700 & 900 \\
\hline 1000 & 1000 & 1000 & 1000 \\
\hline 1000 & 1000 & 1000 & 1000 \\
\hline 1000 & 1000 & 1000 & 1000 \\
\hline
\end{tabular}

ECD Shading Pattern

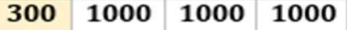

\begin{tabular}{|l|l|l|l|l|}
\hline 500 & 1000 & 1000 & 1000 \\
\hline
\end{tabular}

\begin{tabular}{|l|l|l|l|l|}
\hline 700 & 1000 & 1000 & 1000 \\
\hline
\end{tabular}

\begin{tabular}{|l|l|l|l|}
\hline 900 & 1000 & 1000 & 1000 \\
\hline
\end{tabular}

b

Fig.7. Partial shading patterns (a) schematic to show position of PV modules and the solar insolation level (b) partial shading patterns

In the case of the entire row distribution (ERD) shading condition pattern, the modules in the entire single row are shaded. In this case the modules at the place of $M_{11}, M_{12}, M_{13}, M_{14}$ are subjected to irradiation level of $300 \mathrm{~W} / \mathrm{m}^{2}, 500 \mathrm{~W} / \mathrm{m}^{2}, 700 \mathrm{~W} / \mathrm{m}^{2}$ and $900 \mathrm{~W} / \mathrm{m}^{2}$ while the rest of the modules will receive uniform solar insolation or the irradiance at STC.ERD shading condition pattern has been shown in Figure 7(b).

\subsubsection{Entire Column Distribution (ECD) Shading Pattern}

In the case of the entire column distribution (ERD) shading condition pattern, the modules in the entire single column are shaded. In this case the modules at the place of $M_{11}, M_{12}, M_{13}, M_{14}$ are subjected to irradiation level of $300 \mathrm{~W} / \mathrm{m}^{2}, 500 \mathrm{~W} / \mathrm{m}^{2}, 700 \mathrm{~W} / \mathrm{m}^{2}$ and $900 \mathrm{~W} / \mathrm{m}^{2}$ while the rest of the modules will receive uniform solar insolation or the irradiance at STC.ECD shading condition pattern has been shown in Figure 7(b).

\section{Mathematical Modeling of HCTCT Configuration under PSCs}

The mathematical modeling for the $4 \times 4$ honeycomb total cross-tied (HCTCT) hybrid PV configuration is being done to have detailed insight into the HCTCT configuration scheme characteristics under uniform and PSCs. The mathematical modeling has been performed for ERD and ECD shading condition patterns and the same concept can be extended for subsequent shading patterns or even to more possible partial shading patterns and size of the PV array system. The broader picture of the HCTCT PV array configuration is shown in Figure 8 


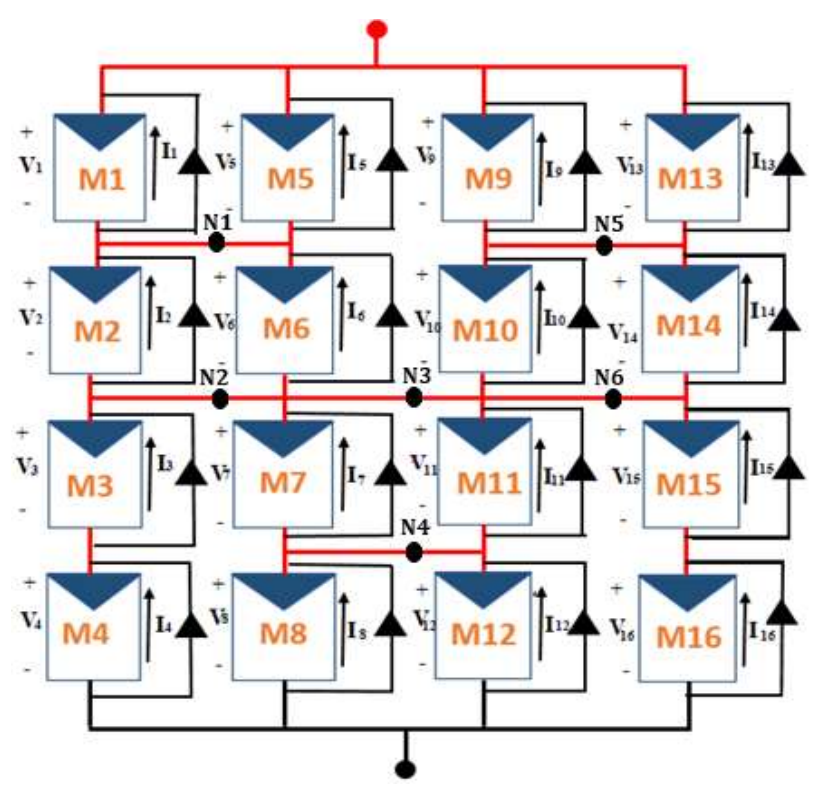

Fig.8. HCTCT PV array configuration broader picture

From Figure 8, by applying Kirchhoff's current law at nodes $N_{1}$ and $N_{2}$, we have;

Similarly, the nodal equations at $N_{3}$ and $N_{4}$ can be given as.

$$
\begin{gathered}
I_{1}+I_{5}=I_{2}+I_{6} \\
I_{2}+I_{6}=I_{3}+I_{7}+I_{8}
\end{gathered}
$$

$$
\begin{gathered}
I_{7}+I_{11}=I_{5}+I_{8}+I_{9}+I_{10} \\
I_{7}+I_{11}=I_{8}+I_{12}
\end{gathered}
$$

The nodal equations for nodes $N_{5}$ and $N_{6}$ can be written as;

$$
\begin{gathered}
I_{9}+I_{13}=I_{10}+I_{14} \\
I_{10}+I_{14}=I_{11}+I_{12}+I_{15}+I_{16}
\end{gathered}
$$

To have voltage equations, applying Kirchhoff's voltage for each loop and we have;

$$
\begin{aligned}
V_{1} & =V_{5} \\
V_{2} & =V_{6} \\
V_{3}+V_{4} & =V_{7}+V_{8} \\
V_{9} & =V_{13} \\
V_{10} & =V_{14} \\
V_{11}+V_{12} & =V_{15}+V_{16}
\end{aligned}
$$

Now, applying Kirchhoff's voltage for the four modules in the first column considering them in a loop, the total output voltage $\left(V_{o}\right)$ in the first column PV modules will be;

$$
\sum_{n=1}^{4} V_{n}=V_{o}
$$

The above-mentioned voltage equation is implementable for the PV modules operating under uniform irradiance conditions and also under PSCs. Based on the above considerations for the voltage and current equations, we can conclude the total output voltage $\left(V_{\text {out }, t}\right)$ and total output current $\left(I_{\text {out }, t}\right)$ equations for the HCTCT PV array configuration as;

$$
\begin{gathered}
V_{\text {out }, t}=V_{1}+V_{2}+V_{3}+V_{4}=V_{13}+V_{14}+V_{15}+V_{16} \\
I_{\text {out }, t}=I_{1}+I_{5}+I_{9}+I_{13}
\end{gathered}
$$

In addition, the shading factor $(\alpha)$ for the ERD and ECD shading condition patterns can be given by Equation (29), wherein $S$ is the solar irradiance under PSCs and $S_{o}$ is the solar irradiance at STC.

$$
\alpha=1-\frac{s}{s_{o}}
$$

Considering the shading factor photo-generated current relation with respect to solar irradiance can be given by Equation (30), wherein $I_{p g, o}$ corresponds to the photo-generated current under STC without any mismatch losses. 


$$
I_{p g}(S)=\frac{s}{s_{o}} I_{p g, o}
$$

The above relation can be extendable to incorporate the short-circuit current $\left(I_{s c}\right)$ and photogenerated current $\left(I_{p g}\right)$ relation considering the shading factor $(\alpha)$ under STC and PSCs and is given by Equation (31) and Equation (32) respectively.

$$
\begin{aligned}
& I_{s c}=1-\frac{S}{1000} I_{p g} \\
& I_{s c}=\frac{(1-\alpha) S}{1000} I_{p g}
\end{aligned}
$$

Now based on the above considerations we will compute the output voltage and output current relations for the ERD and ECD shading condition patterns. The HCTCT PV array configuration with respective shading pattern, current, and voltages is shown in Figure 9.

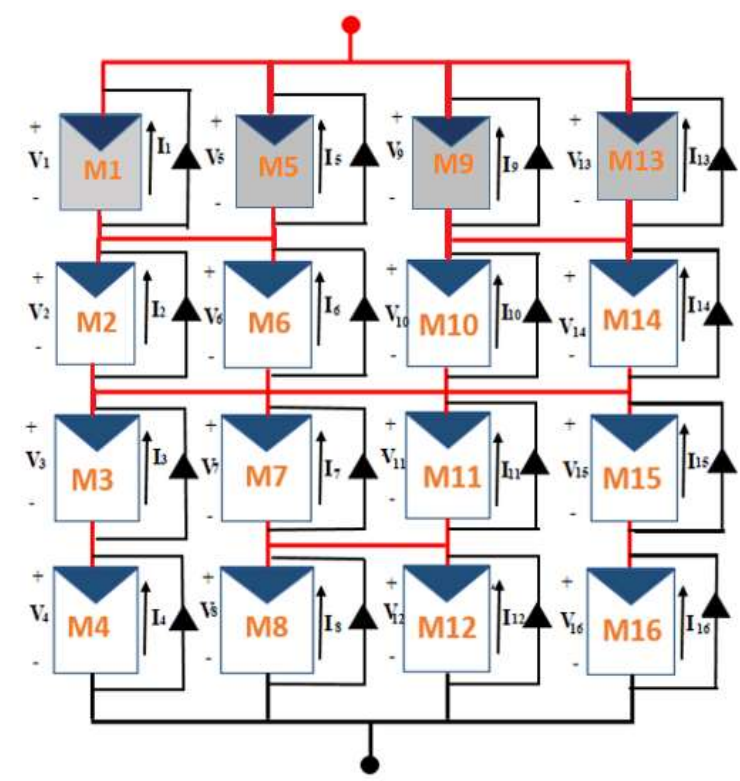

(a)

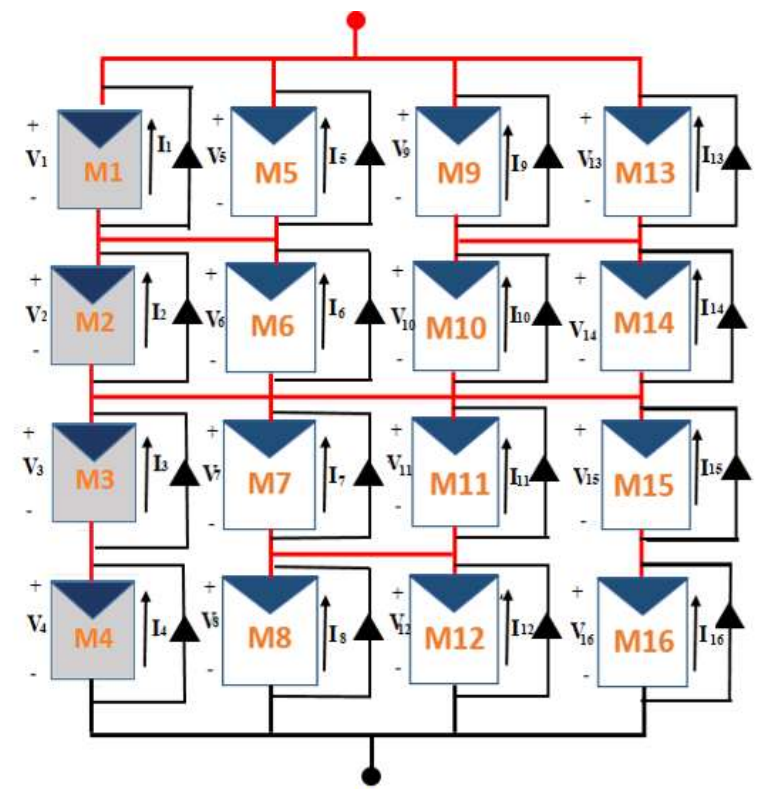

(b)

Fig.9. HCTCT configuration (a) ERD shading pattern (b) ECD Shading pattern

\subsection{Mathematical Modeling for ERD Shading Condition Pattern}

For the case of ERD shading condition, the current expressions can be derived and are given by Equations (33)-(37).

$$
\begin{gathered}
I_{2}=I_{3}=I_{4}=I_{6}=I_{7}=I_{8}=I_{10}=I_{11}=I_{12}=I_{14}=I_{15}=I_{16} \\
I_{16}=I_{p g}-I_{o}\left(\exp \left(\frac{q\left(V_{U S}+I_{p h, m} N_{S} R_{S}\right)}{N_{S} n k T}\right)-1\right)-\left(\frac{V+I_{p h, m N_{s} R_{S}}}{N_{S} R_{p}}\right) \\
V_{U S}=V_{2,3,4,6,7,8,10,11,12,14,15,16}
\end{gathered}
$$

Here $V_{U S}$ represents the voltage across unshaded modules.

$$
\begin{gathered}
I_{1}=I_{2}=I_{3}=I_{4}=I_{p g}-I_{p g} \frac{\alpha S}{1000}-I_{o}\left(\exp \left(\frac{q\left(V_{S M}+I_{p h, m} N_{s} R_{S}\right)}{N_{s} n k T}\right)-1\right)-\left(\frac{V+I_{p h, m} N_{S} R_{S}}{N_{s} R_{p}}\right) \\
V_{S M}=V_{1,5,9,13}
\end{gathered}
$$

Here $V_{S M}$ represents the voltage across unshaded modules. Substituting the Equations (33)-(37) in Equations (27) and (28), the current and voltage relation can be written as;

$$
I_{\text {out }, t}=4 I_{p g}-4 I_{p g} \frac{\alpha S}{1000}-4 I_{o}\left(\exp \left(\frac{q\left(V_{S M}+I_{p h, m} N_{s} R_{S}\right)}{N_{s} n k T}\right)-1\right)-4\left(\frac{V_{S M}+I_{p h, m} N_{s} R_{s}}{N_{s} R_{p}}\right)
$$

Here $I_{\text {out }, t}$ is the total output current. Now considering Equation (27), substitute the Equation (37) in the above equation, we can have the expression as given by Equation (39), wherein $V_{S M 1}$ is the shaded module $M_{1}$ at position $M_{11}$ in PV array system.

$$
\begin{gathered}
I_{\text {out }, t}=4 I_{p g}-4 I_{p g} \frac{\alpha S}{1000}-4 I_{o}\left(\exp \left(\frac{q\left(V_{S M 1}+I_{p h, m} N_{S} R_{S}\right)}{N_{S} k T T}\right)-1\right)-4\left(\frac{V_{S M_{1}+I_{p h, m} N_{S} R_{S}}}{N_{S} R_{p}}\right) \\
V_{S M}=V_{\text {out }, t}-\left(V_{2}+V_{3}\right)-V_{4}
\end{gathered}
$$


From Equations (27) and (30), we can have the nodal voltage values as given by Equations (40) and (41). Substituting the nodal voltage values in Equation (39) gives the total output current of the HCTCT configuration under ERD shading condition patterns.

$$
\begin{aligned}
& V_{4}=\frac{N_{s} n k t}{q}\left[\ln \left(\frac{I_{p h, m}+I_{o}+I_{p h, m} \frac{R s}{R p}-\frac{I_{o u t, t}}{4}}{I_{o}}\right)\right]-I_{p h, m} N_{S} R_{S} \\
& \left(V_{2}+V_{3)}=2 \frac{N_{s} n k t}{q}\left[\ln \left(\frac{I_{p h, m}+I_{o}+I_{p h, m} \frac{R s}{R p} \frac{I_{\text {out }, t}}{4}}{I_{o}}\right)\right]-2 I_{p h, m} N_{S} R_{S}\right.
\end{aligned}
$$

\subsection{Mathematical Modeling for ECD Shading Condition Pattern}

For the case of the ECD shading condition, the current expressions can be derived and are given by Equations (42)-(45).

$$
\begin{gathered}
I_{5}=I_{6}=I_{7}=I_{8}=I_{9}=I_{10}=I_{11}=I_{12}=I_{13}=I_{14}=I_{15}=I_{16} \\
I_{16}=I_{p g}-I_{o}\left(\exp \left(\frac{q\left(V_{U S}+I_{p h, m} N_{S} R_{s}\right)}{N_{S} n k T}\right)-1\right)-\left(\frac{V+I_{p h, m} N_{S} R_{S}}{N_{S} R_{p}}\right) \\
V_{U S}=V_{5,6.7,8,9,10,11,12,13,14,15,16} \\
I_{1}=I_{2}=I_{3}=I_{4}=I_{p g}-I_{p g} \frac{\alpha S}{1000}-I_{o}\left(\exp \left(\frac{q\left(V_{S M}+I_{p h, m} N_{S} R_{S}\right)}{N_{S} n k T}\right)-1\right)-\left(\frac{V+I_{p h, m N_{S}} R_{S}}{N_{S} R_{p}}\right) \\
V_{S M}=V_{1,2,3,4}
\end{gathered}
$$

Substituting the Equations (42)-(46) in Equations (27) and (28), the current and voltage relation can be written as;

$$
I_{\text {out }, t}=4 I_{p g}-I_{p g} \frac{\alpha S}{1000}-4 I_{o}\left(\exp \left(\frac{q\left(V_{1,2,3,4}+I_{p h, m} N_{S} R_{S}\right)}{N_{s} n k T}\right)-1\right)-4\left(\frac{V_{1,2,3,4}+I_{p h, m} N_{S} R_{S}}{N_{S} R_{p}}\right)
$$

And , Now considering Equation (46), substitute the Equation (46) in the above equation, we can have the expression as given by Equations (49), (51), and (53).

$$
\begin{aligned}
& I_{o u t, t}=4 I_{p g}-I_{p g} \frac{\alpha S}{1000}-4 I_{o}\left(\exp \left(\frac{q\left(V_{1}+I_{p h, m} N_{S} R_{S}\right)}{N_{s} n k T}\right)-1\right)-4\left(\frac{V_{1}+I_{p h, m} N_{S} R_{S}}{N_{s} R_{p}}\right)=4 I_{p g}-I_{p g} \frac{\alpha S}{1000}-4 I_{o}\left(\exp \left(\frac{q\left(V_{2}+I_{p h, m} N_{S} R_{S}\right)}{N_{s} n k T}\right)-1\right)-4\left(\frac{V_{2,3,4}+I_{p h, m} N_{S} R_{S}}{N_{s} R_{p}}\right) \\
& V_{1}=V_{2} \\
& I_{o u t, t}=4 I_{p g}-I_{p g} \frac{\alpha S}{1000}-4 I_{o}\left(\exp \left(\frac{q\left(V_{1}+I_{p h, m} N_{s} R_{S}\right)}{N_{s} n k T}\right)-1\right)-4\left(\frac{V_{1}+I_{p h, m} N_{s} R_{s}}{N_{s} R_{p}}\right)=4 I_{p g}-I_{p g} \frac{\alpha S}{1000}-4 I_{o}\left(\exp \left(\frac{q\left(V_{3}+I_{p h, m} N_{s} R_{S}\right)}{N_{s} n k T}\right)-1\right)-4\left(\frac{V_{2,3,4}+I_{p h, m} N_{s} R_{s}}{N_{s} R_{p}}\right) \\
& V_{1}=V_{3} \\
& I_{o u, t}=4 I_{p g}-I_{p g} \frac{\alpha S}{1000}-4 I_{o}\left(\exp \left(\frac{q\left(V_{1}+I_{p h, m} N_{s} R_{S}\right)}{N_{s} n k T}\right)-1\right)-4\left(\frac{V_{1}+I_{p h, m} N_{s} R_{s}}{N_{s} R_{p}}\right)=4 I_{p g}-I_{p g} \frac{\alpha S}{1000}-4 I_{o}\left(\exp \left(\frac{q\left(V_{3}+I_{p h, m} N_{s} R_{S}\right)}{N_{s} n k T}\right)-1\right)-4\left(\frac{V_{2,3,4}+I_{p h, m} N_{s} R_{S}}{N_{s} R_{p}}\right) \\
& V_{1}=V_{4}
\end{aligned}
$$

Considering the Equations (49), (51) and (53), we can have the following expression.

$$
V_{1}=V_{2}=V_{3}=V_{4}
$$

Substituting the expression for voltage relation as obtained from the above expression in Equation (27), we can write voltage expression as;

$$
V_{\text {out }, t}=V_{1}+V_{2}+V_{3}+V_{4}=4 V_{1}
$$

Substituting the voltage expression in Equation (55) in Equation (28) gives the total output current of the HCTCT configuration under ERD shading condition patterns.

$$
I_{\text {out }, t}=4 I_{p g}-I_{p g} \frac{\alpha S}{1000}-4 I_{o}\left(\exp \left(\frac{q\left(\frac{V_{o u t, t}}{4}+I_{p h, m} N_{S} R_{S}\right)}{N_{s} n k T}\right)-1\right)-4\left(\frac{V_{1}+I_{p h, m} N_{s} R_{S}}{N_{s} R_{p}}\right)
$$

5.3 Mathematical Analysis for ERD and ECD shading Cases

This section discusses the numerical analysis of the results obtained in sections 5.1 and 5.2. The investigation for the HCTCT configuration under ERD and ECD shading condition patterns is as follows;

1. For the case of ERD shading condition, the study concludes that under the PSCs compared to the unshaded case, the value of short circuit current $\left(I_{s c}\right)$ is not changed and due to $\ln$ relation in Equation (32), HCTCT configuration I-V relation has 4 peaks. The point where the currentvoltage (I-V) curve changes $\left(I_{s h d}\right)$ its direction is given by $4 I_{p g}-\frac{4 \alpha S}{100} I_{p g}$. It is to be noted that $I_{s h d}$ corresponds to the current where current- 
voltage characteristics change path or direction because of the shading effects and the emergence of the new peak depends upon the shading factor $(\alpha)$.

2. For the case of ERD shading condition, the study concludes that under the PSCs compared to the unshaded case, the value of short circuit current $\left(I_{s c}\right)$ is changed and equals to $4 I_{p g}-\frac{\alpha S}{100} I_{p g}$. In this case, HCTCT configuration has 2 peaks and there will change in the current direction $\left(I_{\text {shd }}\right)$ under this particular shading condition.

The numerical analysis summarized in Table 2 is verified able with the simulation results discussed in sections 6.7 and 6.8 respectively and the mathematical modeling results for the HCTCT configuration under ERD and ECD shading conditions are quite satisfied with the simulation results showing that accurate modeling has been performed for the proposed HCTCT hybrid PV array configuration.

Table 2

Numerical Analysis Summary of HCTCT Configuration under ERD and ECD Shading Patterns

\begin{tabular}{cccc}
\hline $\begin{array}{c}\text { Tested Shading } \\
\text { Conditions }\end{array}$ & $\boldsymbol{I}_{\boldsymbol{s c}}$ & $\boldsymbol{I}_{\text {shd }}$ & Number of Peaks \\
\hline ERD & $4 I_{p g}$ & $4 I_{p g}-4 \alpha I_{p g}$ & $4(3 \mathrm{GMPP}+1$ \\
& & & LMPP) \\
ECD & $4 I_{p g}-\alpha I_{p g}$ & $4 I_{p g}-\alpha I_{p g}$ & $2(1 \mathrm{GMPP}+1$ \\
& & & LMPP) \\
\hline
\end{tabular}

\section{Simulation Results and Performance Assessment}

The performance assessment of each of the PV array topologies under partial shading pattern variants considering the maximum power generated $\left(\mathrm{P}_{\mathrm{mp}}\right)$, mismatch power loss $\left(\Delta \mathrm{P}_{\mathrm{ml}}\right)$, relative power loss $\left(\mathrm{P}_{\mathrm{rl}}\right)$ and the fill factor $(\mathrm{FF})$ is discussed in this section. The values have been extracted by simulating each of the PV array topologies under shading patterns based on the methodology illustrated in Figure 1 and Figure 2.

\subsection{Standard Test Conditions (STC)}

Under uniform irradiance conditions or STC $\left(1000 \mathrm{~W} / \mathrm{m}^{2}\right.$ and $\left.25^{\circ} \mathrm{C}\right)$, there will be no emergence of multiple maxima and all the PV array configurations exhibit unique global maximum power point (GMPP). The LMPP does not exist under STC conditions. The maximum power generated by all PV array is the same and is equal to $3997 \mathrm{~W}$. The fill factor of all PV array configuration is approximately the same and is equal to $79.02 \%$. Further details regarding the open-circuit voltage $\left(V_{o c}\right)$, short circuit current $\left(I_{s c}\right)$, global and peak point parameters including the power generated at maximum power point $\left(P_{m p}\right)$, the voltage at maximum power point $\left(V_{m p}\right)$, the current produced at the maximum power point $\left(I_{m p}\right)$ is are provided in Table 3.The mismatch power loss $\left(\Delta \mathrm{P}_{\mathrm{ml}}\right)$ for all the array configurations is quite less and is $0.058 \%$.For standard test conditions, $\Delta \mathrm{P}_{\mathrm{ml}}$ is calculated based on the rated parameters of the module. Moreover, the series $(\mathrm{S})$ and parallel $(\mathrm{P})$ array configurations show differentiating voltage and current characteristics as compared to the rest of the PV array topologies. Figure 10 graphically depicts the comparative analysis of all the array configurations in terms of maximum power generated and the mismatch power losses.

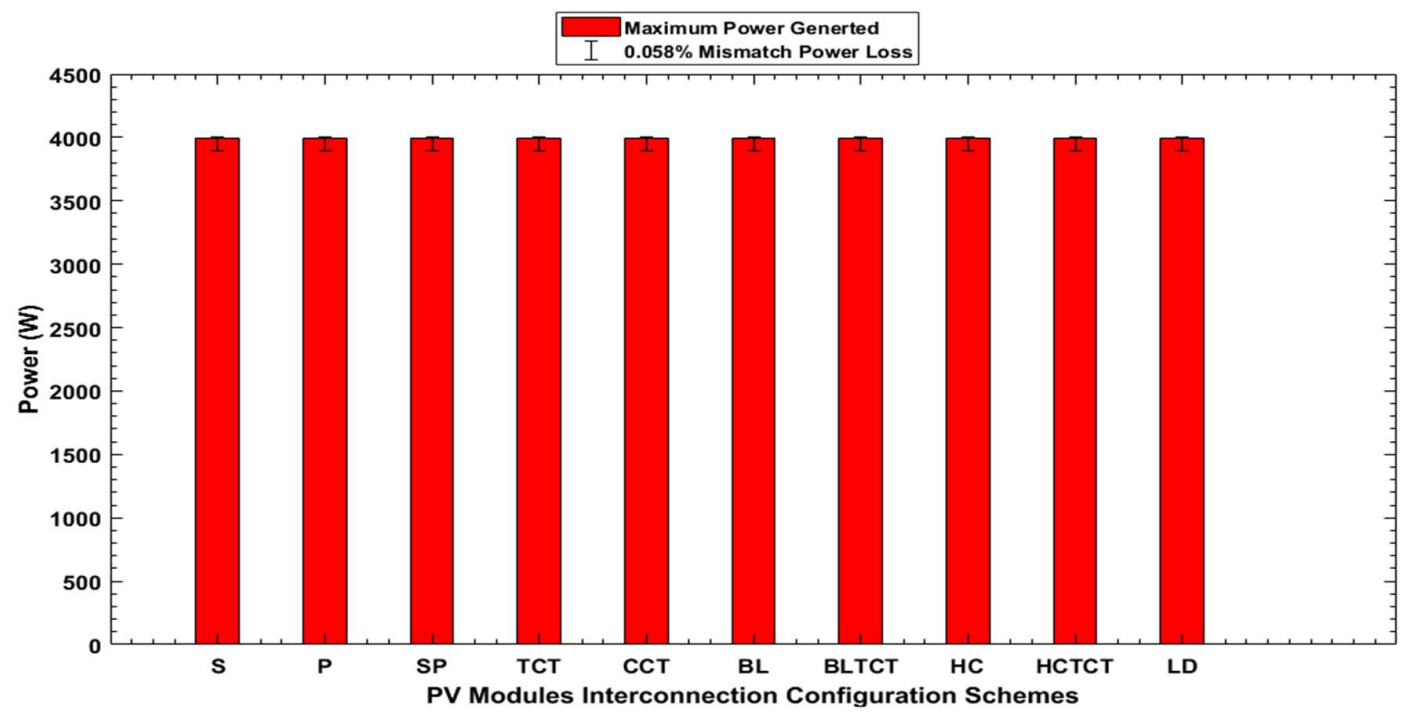

Fig.10. Maximum power generation and mismatch power losses of PV modules interconnection configuration schemes under standard testing conditions 


\subsection{SN Shading Pattern}

Under SN partial shading conditions compared to the STC, it has been observed that all the PV array configurations are prone to multiple maximas and as a result power mismatch losses are significant in each configuration except the parallel $(\mathrm{P})$ array configuration which still exhibits the unique GMPP with minimum $\Delta \mathrm{P}_{\mathrm{ml}}$ among all configurations and is $7.6 \%$ with maximum power generation. However, after P configuration, TCT array topology yields the maximum power generation with the value $3501 \mathrm{~W}$ and mismatch power losses are $12.41 \%$. Moreover, HCTCT configuration also yields the maximum power generation after P and TCT array configurations. The number of peaks (NOPs) generated in each configuration under SN PSC are two except P configuration which gives a single peak Further details regarding the open-circuit voltage $\left(V_{o c}\right)$, short circuit current $\left(I_{s c}\right)$, global and peak point parameters including the power generated at maximum power point $\left(P_{m p}\right)$, the voltage at maximum power point $\left(V_{m p}\right)$, the current produced at the maximum power point $\left(I_{m p}\right)$ is are provided in Table 3. The comparative analysis of all the array configurations in terms of maximum power generated and the mismatch power losses have been illustrated in Figure 11 and Figure 12 respectively. The relative power loss $\left(\mathrm{P}_{\mathrm{rl}}\right)$ is calculated based on Equations (8) and (9).The relative power loss $\left(\mathrm{P}_{\mathrm{rl}}\right)$ for the S, P, SP, TCT, BL,BLTCT ,HC,HCTCT and LD PV modules interconnection configuration schemes is $211,7,383,199,241$, $307,241,293$ and 222 respectively and is graphically illustrated in Figure 13.It can be observed TCT configuration gives the better energy output and has the least mismatch power loss and relative power loss after $P$ array configuration.

\subsection{SW Shading Pattern}

The Series PV array configuration I-V and I-P characteristics are significantly affected under SW partial shading pattern and the mismatch power losses reach to $50.91 \%$ and the generated power drops down to $1962 \mathrm{~W}$. The parallel configuration is least affected under this shading pattern and has minimal mismatch losses. However, TCT configuration yields more energy output equals to $2833 \mathrm{~W}$ and has minimal mismatch losses as compared to other configurations after P array configuration. However, BLTCT configuration also yields maximum power generation quite closer to the TCT configuration with the value $2803 \mathrm{~W}$. CCT and HCTCT generated $2783 \mathrm{~W}$ whereas LD yields minimal power after $\mathrm{S}$ array configuration. The number of peaks generated in $\mathrm{S}$ array configuration is four while all other configurations tend to produce two peaks except $\mathrm{P}$ array configuration which again exhibits a unique peak under SN PSC. Further details regarding the open-circuit voltage $\left(V_{o c}\right)$, short circuit current $\left(I_{s c}\right)$, global and peak point parameters including the power generated at maximum power point $\left(P_{m p}\right)$, the voltage at maximum power point $\left(V_{m p}\right)$, the current produced at the maximum power point $\left(I_{m p}\right)$ is are provided in Table 3 
Table 3

PV Modules Configurations Parameter variations under Shading Conditions

\begin{tabular}{|c|c|c|c|c|c|c|c|c|c|c|c|}
\hline & \multirow{2}{*}{ Topology } & \multirow{2}{*}{$\begin{array}{l}V_{o c} \\
(\mathbf{V})\end{array}$} & \multirow{2}{*}{$\begin{array}{l}\boldsymbol{I}_{\boldsymbol{s c}} \\
(\mathbf{A})\end{array}$} & \multicolumn{3}{|c|}{ Global Peak Point Parameters } & \multicolumn{3}{|c|}{ Local Peak Point Parameters } & \multirow{2}{*}{$\begin{array}{l}\text { FF } \\
(\%)\end{array}$} & \multirow{2}{*}{$\begin{array}{r}\Delta \mathbf{P}_{\mathrm{ml}} \\
(\%)\end{array}$} \\
\hline & & & & $\begin{array}{l}\boldsymbol{P}_{\boldsymbol{m p}} \\
(\mathbf{W})\end{array}$ & $\begin{array}{l}V_{m p} \\
\text { (V) }\end{array}$ & $\begin{array}{l}I_{m p} \\
(A)\end{array}$ & $\begin{array}{l}\boldsymbol{P}_{m p} \\
(\mathbf{W})\end{array}$ & $\begin{array}{l}V_{m p} \\
(\mathbf{V})\end{array}$ & $\begin{array}{l}\boldsymbol{I}_{\boldsymbol{m} p} \\
(\mathbf{A})\end{array}$ & & \\
\hline \multicolumn{12}{|c|}{ STC conditions } \\
\hline & $\mathrm{S}$ & 814.8 & 6.207 & 3997.0 & 688.0 & 5.81 & - & - & - & 79.03 & 0.058 \\
\hline & $P$ & 50.93 & 99.31 & 3997.0 & 43.0 & 94.96 & - & - & - & 79.02 & 0.058 \\
\hline & SP & 203.7 & 24.83 & 3997.0 & 172.2 & 23.22 & - & - & - & 79.02 & 0.058 \\
\hline & TCT & 203.6 & 24.83 & 3997.0 & 171.5 & 23.32 & - & - & - & 79.06 & 0.058 \\
\hline & CCT & 203.7 & 24.83 & 3997.0 & 172.5 & 23.17 & - & - & - & 79.02 & 0.058 \\
\hline & BL & 203.7 & 24.83 & 3997.0 & 170.0 & 23.51 & - & - & - & 79.02 & 0.058 \\
\hline & BLTCT & 203.7 & 24.83 & 3997.0 & 172.5 & 23.17 & - & - & - & 79.02 & 0.058 \\
\hline & $\mathrm{HC}$ & 203.7 & 24.83 & 3997.0 & 172.5 & 23.17 & - & - & - & 79.02 & 0.058 \\
\hline & НСТСТ & 203.7 & 24.83 & 3997.0 & 171.5 & 23.3 & - & - & - & 79.02 & 0.058 \\
\hline & LD & 203.6 & 24.83 & 3997.0 & 172.5 & 23.11 & - & - & - & 79.06 & 0.058 \\
\hline
\end{tabular}

b. SN shading Pattern

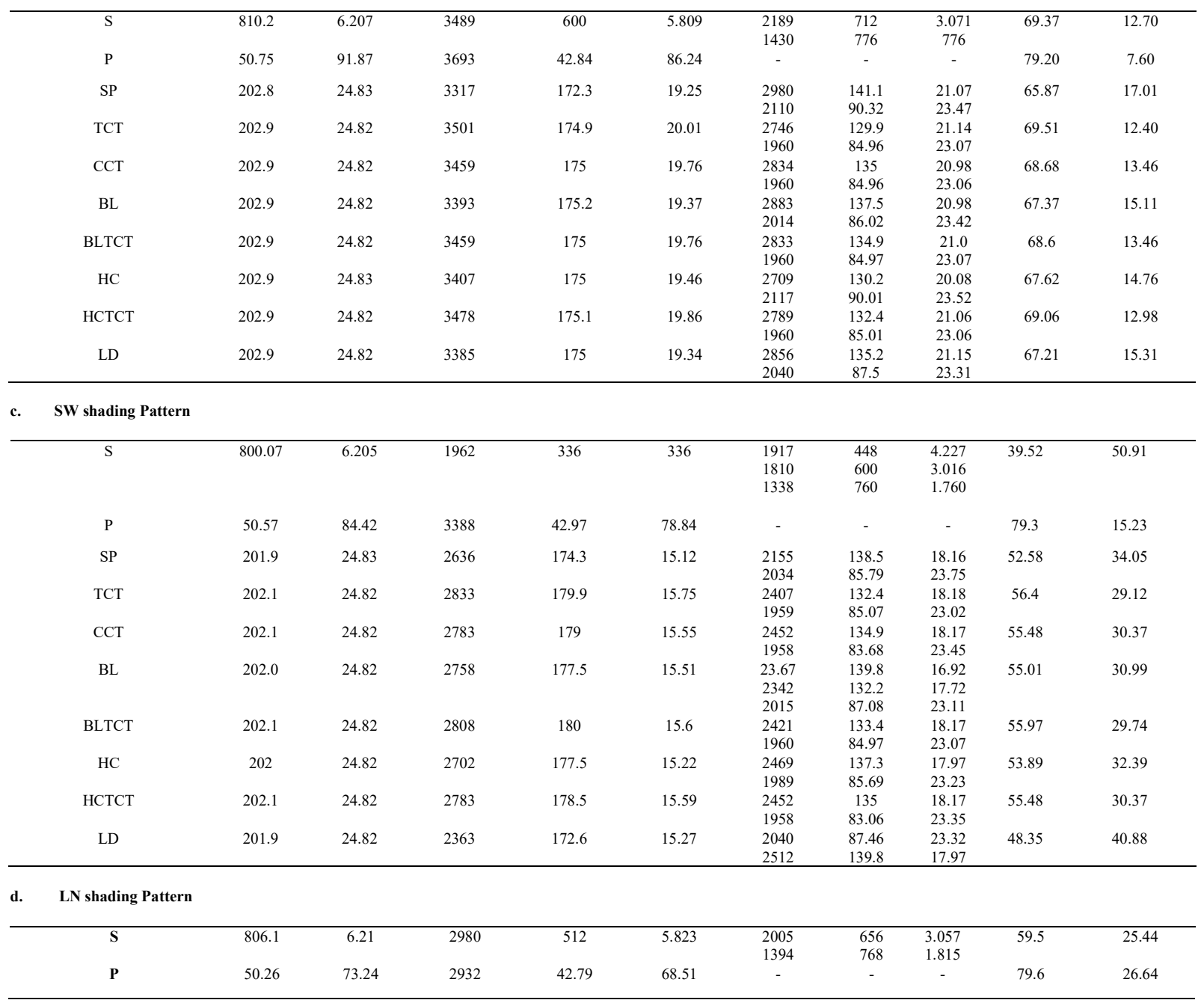




\begin{tabular}{|c|c|c|c|c|c|c|c|c|c|c|}
\hline \multirow{2}{*}{ Topology } & \multirow{2}{*}{$\begin{array}{l}V_{o c} \\
(\mathbf{V})\end{array}$} & \multirow{2}{*}{$\begin{array}{l}\boldsymbol{I}_{s c} \\
(\mathbf{A})\end{array}$} & \multicolumn{3}{|c|}{ Global Peak Point Parameters } & \multicolumn{3}{|c|}{ Local Peak Point Parameters } & \multirow{2}{*}{$\begin{array}{l}\text { FF } \\
(\%) \\
\end{array}$} & \multirow{2}{*}{$\begin{array}{r}\Delta \mathbf{P}_{\mathrm{ml}} \\
(\%)\end{array}$} \\
\hline & & & $\begin{array}{l}\boldsymbol{P}_{\boldsymbol{m p}} \\
(\boldsymbol{W})\end{array}$ & $\begin{array}{l}V_{m p} \\
(\mathbf{V})\end{array}$ & $\begin{array}{l}I_{m p} \\
(A)\end{array}$ & $\begin{array}{l}\boldsymbol{P}_{\boldsymbol{m} p} \\
(\mathbf{W})\end{array}$ & $\begin{array}{l}V_{m p} \\
\text { (V) }\end{array}$ & $\begin{array}{l}I_{m p} \\
(\mathbf{A})\end{array}$ & & \\
\hline SP & 200.9 & 21.09 & 2627 & 174.7 & 15.04 & $\begin{array}{l}2277 \\
1619 \\
829.1\end{array}$ & $\begin{array}{l}135.9 \\
88.08 \\
40.69\end{array}$ & $\begin{array}{l}16.67 \\
18.22 \\
20.39\end{array}$ & 62.00 & 34.27 \\
\hline TCT & 201.0 & 21.08 & 2754 & 175.1 & 15.72 & $\begin{array}{l}2181 \\
1520 \\
799.4\end{array}$ & $\begin{array}{c}130 \\
85.39 \\
40.11\end{array}$ & $\begin{array}{l}16.77 \\
17.83 \\
19.91\end{array}$ & 64.99 & 31.09 \\
\hline CCT & 200.9 & 21.09 & 2711 & 174.9 & 15.50 & $\begin{array}{l}2235 \\
1480 \\
838.9\end{array}$ & $\begin{array}{c}132.6 \\
83.8 \\
42.46\end{array}$ & $\begin{array}{l}16.86 \\
17.83 \\
19.76\end{array}$ & 63.98 & 32.17 \\
\hline BL & 210 & 21.09 & 2725 & 175.1 & 15.55 & $\begin{array}{c}2167 \\
1574 \\
811.1\end{array}$ & $\begin{array}{l}131.3 \\
87.66 \\
40.08\end{array}$ & $\begin{array}{c}16.5 \\
17.96 \\
20.23\end{array}$ & 61.2 & 31.82 \\
\hline BLTCT & 201 & 21.09 & 2733 & 174.9 & 15.63 & $\begin{array}{l}2202 \\
1499 \\
807.3\end{array}$ & $\begin{array}{c}130 \\
83.52 \\
39.73\end{array}$ & $\begin{array}{l}16.94 \\
17.95 \\
20.32\end{array}$ & 64.47 & 31.62 \\
\hline $\mathrm{HC}$ & 200.9 & 21.09 & 2678 & 174.6 & 15.34 & $\begin{array}{l}2210 \\
1631 \\
811.1\end{array}$ & $\begin{array}{l}132.8 \\
90.48 \\
39.98\end{array}$ & $\begin{array}{l}16.64 \\
18.01 \\
20.29\end{array}$ & 63.20 & 32.99 \\
\hline HCTCT & 201 & 21.09 & 2724 & 175.1 & 15.55 & $\begin{array}{l}2215 \\
1502 \\
813.3\end{array}$ & $\begin{array}{c}131.5 \\
84.1 \\
41.37\end{array}$ & $\begin{array}{c}16.84 \\
17.7 \\
19.68\end{array}$ & 64.25 & 31.84 \\
\hline LD & 200.9 & 21.09 & 2635 & 173.2 & 15.22 & $\begin{array}{c}2286 \\
1592 \\
832 \\
\end{array}$ & $\begin{array}{l}135.4 \\
88.34 \\
41.24 \\
\end{array}$ & $\begin{array}{l}16.88 \\
18.02 \\
20.19 \\
\end{array}$ & 62.19 & 34.07 \\
\hline
\end{tabular}

a. LW shading Pattern

\begin{tabular}{|c|c|c|c|c|c|c|c|c|c|c|}
\hline $\mathbf{S}$ & 793.1 & 6.202 & 1361 & 448 & 3.039 & $\begin{array}{c}1299 \\
1142 \\
1353 \\
1305 \\
942.4\end{array}$ & $\begin{array}{l}304 \\
208 \\
456 \\
128 \\
160\end{array}$ & $\begin{array}{l}4.273 \\
5.489 \\
2.965 \\
6.143 \\
5.844\end{array}$ & 27.66 & 65.94 \\
\hline $\mathbf{P}$ & 49.82 & 59.59 & 2376 & 42.33 & 56.12 & - & - & - & 80.03 & 40.55 \\
\hline SP & 199.9 & 20.47 & 2119 & 171.9 & 12.33 & 779.1 & 42.37 & 18.41 & 51.78 & 46.98 \\
\hline TCT & 199.1 & 20.46 & 2141 & 172.1 & 12.44 & 774 & 40.18 & 19.18 & 52.56 & 46.43 \\
\hline CCT & 199.1 & 20.47 & 2115 & 172.1 & 12.29 & 787 & 40.06 & 19.42 & 51.89 & 47.08 \\
\hline BL & 199 & 20.47 & 2116 & 171.7 & 12.32 & 785.2 & 40.94 & 19.21 & 51.94 & 47.06 \\
\hline BLTCT & 199 & 20.47 & 2115 & 172.4 & 12.27 & 786 & 40.57 & 19.39 & 51.92 & 47.08 \\
\hline $\mathrm{HC}$ & 199 & 20.47 & 2118 & 172.2 & 12.3 & 785.7 & 40.91 & 19.2 & 51.99 & 47.01 \\
\hline HCTCT & 199 & 20.47 & 2115 & 172.2 & 12.28 & 786.1 & 40.54 & 19.41 & 51.92 & 47.08 \\
\hline LD & 199 & 20.46 & 2137 & 172.4 & 12.39 & 775.9 & 40.01 & 19.4 & 52.48 & 46.53 \\
\hline
\end{tabular}

f. D shading Pattern

\begin{tabular}{|c|c|c|c|c|c|c|c|c|c|c|}
\hline S & 809.2 & 6.207 & 3131 & 568 & 5.531 & $\begin{array}{l}2976 \\
2773 \\
2184 \\
1427\end{array}$ & $\begin{array}{l}504 \\
648 \\
712 \\
776\end{array}$ & $\begin{array}{l}5.905 \\
4.279 \\
3.068 \\
1.834\end{array}$ & 62.33 & 21.66 \\
\hline $\mathbf{P}$ & 50.73 & 89.38 & 3592 & 42.84 & 83.85 & - & - & - & 79.21 & 10.13 \\
\hline SP & 202.5 & 24.83 & 2980 & 128.2 & 23.2 & 2582 & 178.6 & 14.45 & 59.26 & 25.44 \\
\hline TCT & 202.7 & 24.19 & 3474 & 174.9 & 19.87 & $\begin{array}{r}2703 \\
1840 \\
907.2\end{array}$ & $\begin{array}{c}129 \\
82.38 \\
39.1\end{array}$ & $\begin{array}{c}20.95 \\
22.31 \\
23.3\end{array}$ & 70.85 & 13.08 \\
\hline CCT & 202.6 & 24.82 & 2979 & 177.5 & 16.77 & $\begin{array}{l}2808 \\
2033\end{array}$ & $\begin{array}{l}131.1 \\
85.65\end{array}$ & $\begin{array}{c}21.4 \\
23.74\end{array}$ & 59.24 & 25.46 \\
\hline BL & 202.5 & 24.83 & 2981 & 127.5 & 23.37 & 2617 & 180 & 14.54 & 59.28 & 25.41 \\
\hline BLTCT & 202.6 & 24.82 & 3011 & 180 & 16.72 & $\begin{array}{l}2809 \\
1994\end{array}$ & $\begin{array}{l}130.2 \\
85.06\end{array}$ & $\begin{array}{l}27.56 \\
23.46\end{array}$ & 59.87 & 24.66 \\
\hline HC & 202.7 & 24.82 & 3389 & 175.3 & 19.33 & $\begin{array}{c}2704 \\
1833 \\
969.2\end{array}$ & $\begin{array}{l}130.1 \\
85.23 \\
40.56\end{array}$ & $\begin{array}{c}20.78 \\
22.9 \\
23.98\end{array}$ & 67.36 & 15.21 \\
\hline HCTCT & 202.7 & 24.81 & 3446 & 174.9 & 19.72 & $\begin{array}{l}2730 \\
1781 \\
954.7\end{array}$ & $\begin{array}{l}129.9 \\
81.58 \\
40.71\end{array}$ & $\begin{array}{l}21.02 \\
21.84 \\
22.94\end{array}$ & 68.52 & 13.78 \\
\hline LD & 202.7 & 24.82 & 3219 & 177.6 & 18.12 & $\begin{array}{l}2645 \\
1988 \\
\end{array}$ & $\begin{array}{c}130 \\
86.75 \\
\end{array}$ & $\begin{array}{l}20.35 \\
22.93 \\
\end{array}$ & 63.98 & 19.46 \\
\hline ERD shadin & & & & & & & & & & \\
\hline $\mathrm{S}$ & 809.1 & 6.207 & 3132 & 569.7 & 5.50 & $\begin{array}{l}2980 \\
2769 \\
2182 \\
1425\end{array}$ & $\begin{array}{l}510.7 \\
644.5 \\
713.1 \\
772.7\end{array}$ & $\begin{array}{l}5.84 \\
4.29 \\
3.05 \\
1.84\end{array}$ & 62.36 & 21.64 \\
\hline$P$ & 50.69 & 89.38 & 3592 & 42.73 & 84.10 & - & - & - & 79.28 & 10.13 \\
\hline SP & 202.7 & 24.2 & 3316 & 172.5 & 19.24 & $\begin{array}{c}2933 \\
2002 \\
976\end{array}$ & $\begin{array}{l}138.5 \\
89.55 \\
41.38\end{array}$ & $\begin{array}{l}21.17 \\
22.35 \\
23.61\end{array}$ & 67.59 & 17.03 \\
\hline
\end{tabular}




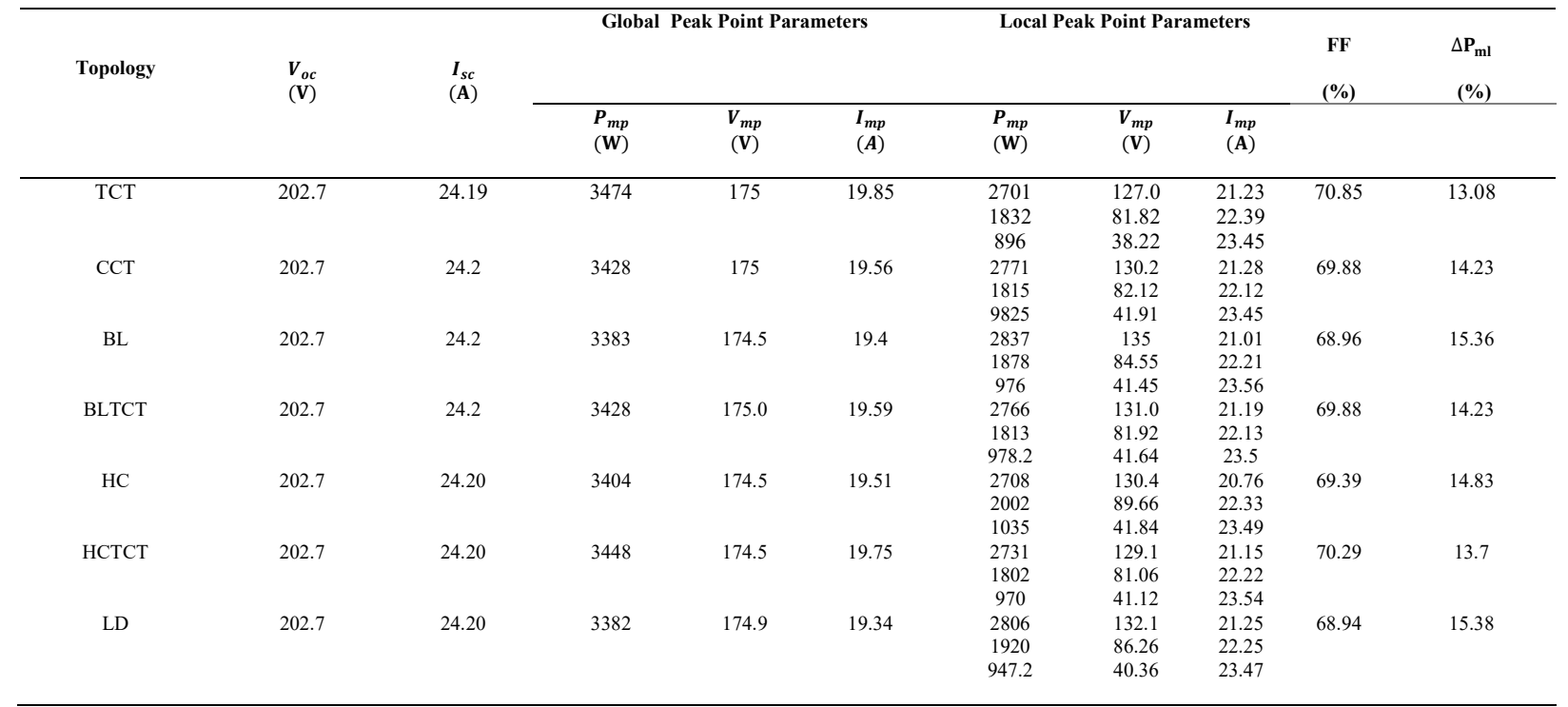

h. ECD shading Pattern

\begin{tabular}{|c|c|c|c|c|c|c|c|c|c|c|}
\hline $\mathbf{S}$ & 809.2 & 6.207 & 3133 & 569.5 & 5.501 & $\begin{array}{l}2974 \\
2772 \\
2182 \\
1417\end{array}$ & $\begin{array}{l}503.2 \\
645.2 \\
713.0 \\
775.5\end{array}$ & $\begin{array}{c}5.91 \\
4.29 \\
3.05 \\
1.825\end{array}$ & 62.37 & 21.61 \\
\hline $\mathbf{P}$ & 50.69 & 89.38 & 3592 & 42.73 & 84.10 & - & - & - & 79.28 & 10.10 \\
\hline SP & 202.5 & 24.83 & 2981 & 127.5 & 23.38 & 2582 & 179.9 & 14.36 & 59.28 & 25.41 \\
\hline TCT & 202.6 & 24.83 & 2981 & 127.7 & 23.34 & 2660 & 184.3 & 14.53 & 59.23 & 25.44 \\
\hline CCT & 202.6 & 24.83 & 2981 & 127.5 & 23.38 & 2647 & 182.5 & 14.49 & 59.25 & 25.41 \\
\hline BL & 202.5 & 24.83 & 2981 & 127.5 & 23.39 & 2637 & 182.0 & 14.49 & 59.28 & 25.41 \\
\hline BLTCT & 202.5 & 24.83 & 2982 & 127.5 & 23.38 & 2648 & 182.5 & 14.51 & 59.30 & 25.39 \\
\hline HC & 202.5 & 24.83 & 2981 & 127.5 & 23.38 & 2642 & 182.3 & 14.49 & 59.28 & 25.41 \\
\hline НСТCТ & 202.6 & 24.83 & 2981 & 127.5 & 23.39 & 2655 & 182.4 & 14.55 & 59.25 & 25.41 \\
\hline LD & 202.5 & 24.83 & 2981 & 127.5 & 23.37 & 2611 & 179.7 & 14.53 & 59.28 & 25.41 \\
\hline
\end{tabular}

The comparative analysis of all the array configurations in terms of maximum power generated and the mismatch power losses graphically have been shown in Figure 11 and Figure 12 respectively. The relative power loss $\left(\mathrm{P}_{\mathrm{rl}}\right)$ is calculated based on Equations (8) and (9).The relative power loss $\left(\mathrm{P}_{\mathrm{rl}}\right)$ for the S, P, SP, TCT, BL,BLTCT ,HC,HCTCT and LD PV modules interconnection configuration schemes is 1438, 12 , 764, 567, 617, 642, 592, 698, 617 and 1037 respectively and is graphically shown in Figure 13.It can be observed TCT configuration gives the better energy output and has the least mismatch power loss and relative power loss after $\mathrm{P}$ array configuration.

\subsection{LN Pattern}

Under LN shading condition, S configuration yields maximum power equals $2980 \mathrm{~W}$. Parallel and total cross-tied array configurations yield the maximum power $2932 \mathrm{~W}$ and $2754 \mathrm{~W}$ respectively after S configuration. Maximum mismatch power loss is in LD configuration. In this case, S configuration generated three NOP on output I-V and P-V characteristics while all other PV array configurations generated four NOPs except P array topology which exhibits a unique peak powerpoint. Further details regarding PV array topology characteristics are given in Table 3. The comparative analysis of all the array configurations in terms of maximum power generated and the mismatch power losses has been illustrated in Figure 11 and Figure 12 respectively. The relative power loss $\left(\mathrm{P}_{\mathrm{rl}}\right)$ is calculated based on Equations (8) and (9).The relative power loss $\left(\mathrm{P}_{\mathrm{rl}}\right)$ for the S, P, SP, TCT, BL, BLTCT,HC, HCTCT, and LD PV modules interconnection configuration schemes is 1, 18, 323, 196, 239, 225, $217,272,216$, and 315 respectively and is illustrated in Figure 13.

\subsection{LW Pattern}

Under LW shading condition, the third fourth of the PV modules in array configurations are shaded. S configuration power is drastically reduced under LW shading conditions due to the series connection of modules. P configuration yields maximum power equals $2376 \mathrm{~W}$. TCT and LD array configurations yield the maximum power $2141 \mathrm{~W}$ and $2137 \mathrm{~W}$ respectively after P configuration. Maximum mismatch power loss is in S configuration. In this case, $\mathrm{S}$ configuration generated six NOPs on output I-V and P-V characteristics while all other PV array configurations generated two NOP except $\mathrm{P}$ array topology which exhibits a unique peak powerpoint. Further details regarding PV array topology characteristics 
are given in Table 3. The comparative analysis of all the array configurations in terms of maximum power generated and the mismatch power losses have been illustrated in Figure 11 and Figure 12 respectively. The relative power loss $\left(\mathrm{P}_{\mathrm{rl}}\right)$ is calculated based on Equations (8) and (9).The relative power loss $\left(\mathrm{P}_{\mathrm{rl}}\right)$ for the S, P, SP, TCT, BL,BLTCT ,HC,HCTCT and LD PV modules interconnection configuration schemes is 1039, 24, 281, 259, 285, 284, 285, 282, 285 and 263 respectively and is illustrated in Figure 13.

\subsection{Pattern}

In this case, the P array configuration yields the maximum power out among all configurations and is $3592 \mathrm{~W}$. Afterwards, TCT and HCTCT configuration generated the maximum power equals to $3474 \mathrm{~W}$ and $3446 \mathrm{~W}$ respectively. SP yields the minimum power generation. . In this case $\mathrm{S}$ configuration generated five NOP on output I-V and P-V characteristics while S exhibited a unique number of a peak, SP and BL configurations generated two NOP, CCT and BLTCT generated two NOPs, and TCT, HC, and TCT generated four NOP. Further details regarding PV array topology characteristics are given in Table 4 . The comparative analysis of all the array configurations in terms of maximum power generated and the mismatch power losses have been illustrated in Figure 11 and Figure 12 respectively. The relative power loss $\left(\mathrm{P}_{\mathrm{rl}}\right)$ is calculated based on Equations (8) and (9).The relative power loss $\left(\mathrm{P}_{\mathrm{rl}}\right)$ for the S, P, SP, TCT, BL,BLTCT, HC,HCTCT and LD PV modules interconnection configuration schemes is $469,8,620,126,621,619,589,211,154$ and 381 respectively and is graphically shown in Figure 13.

\subsection{ERD Pattern}

The mathematical modeling for the HCTCT array topology discussed in sub-section 5.2 is verifiable from the simulation results enlisted in Table 3. The numerical analysis discussed in section 5.3 pointed out that there will be four NOPs for HCTCT configuration under ERD shading condition and the table depicts that simulation results verified the mathematical modeling. From the maximum power generation perspective, the $\mathrm{P}$ array configuration yields the maximum power output among all configurations with the value $3592 \mathrm{~W}$, and then TCT, HCTCT, CCT, BL subsequently extract the maximum power output. In this case, the S configuration generated five NOP on output I-V and P-V characteristics while all other configurations generated four NOP except $\mathrm{P}$ array configuration which exhibited the unique number of the peak. The comparative analysis of all the array configurations in terms of maximum power generated and the mismatch power losses have been shown graphically in has been illustrated in Figure 11 and Figure 12 respectively.. The relative power loss $\left(\mathrm{P}_{\mathrm{rl}}\right)$ is calculated based on Equations (8) and (9).The relative power loss $\left(\mathrm{P}_{\mathrm{rl}}\right)$ for the S, P, SP, TCT, BL,BLTCT ,HC,HCTCT and LD PV modules interconnection configuration schemes is 468, 8, 284, 126, 172, 217, 172, 196, 152 and 218 respectively and is depicted in Figure 13.

\subsection{ECD Pattern}

The mathematical modeling for HCTCT array topology discussed in sub-section 5.3 is verifiable from the simulation results enlisted in Table 3. The numerical analysis discussed in section 5.3 pointed out that there will be four NOPs for HCTCT configuration under ECD shading condition and the table depicts that simulation results verified the mathematical modeling. From the maximum power generation perspective, $\mathrm{P}$ array configuration yields the maximum power output among all configurations with the value $3592 \mathrm{~W}$. In this case $\mathrm{S}$ configuration generated five NOP on output I-V and P-V characteristics while all other configurations generated two NOP except P array configuration which exhibited unique number of peak._The comparative analysis of all the array configurations in terms of maximum power generated and the mismatch power losses has been illustrated in Figure 11 and Figure 12 respectively. The relative power loss $\left(\mathrm{P}_{\mathrm{rl}}\right)$ is calculated based on Equations (8) and (9). The relative power loss $\left(\mathrm{P}_{\mathrm{rl}}\right)$ for the S, P, SP, TCT, BL,BLTCT ,HC,HCTCT and LD PV modules interconnection configuration schemes is 467, 8,6 19, 620, 619, 619, 618, 619, 619 and 619 respectively and is graphically shown in Figure 13.

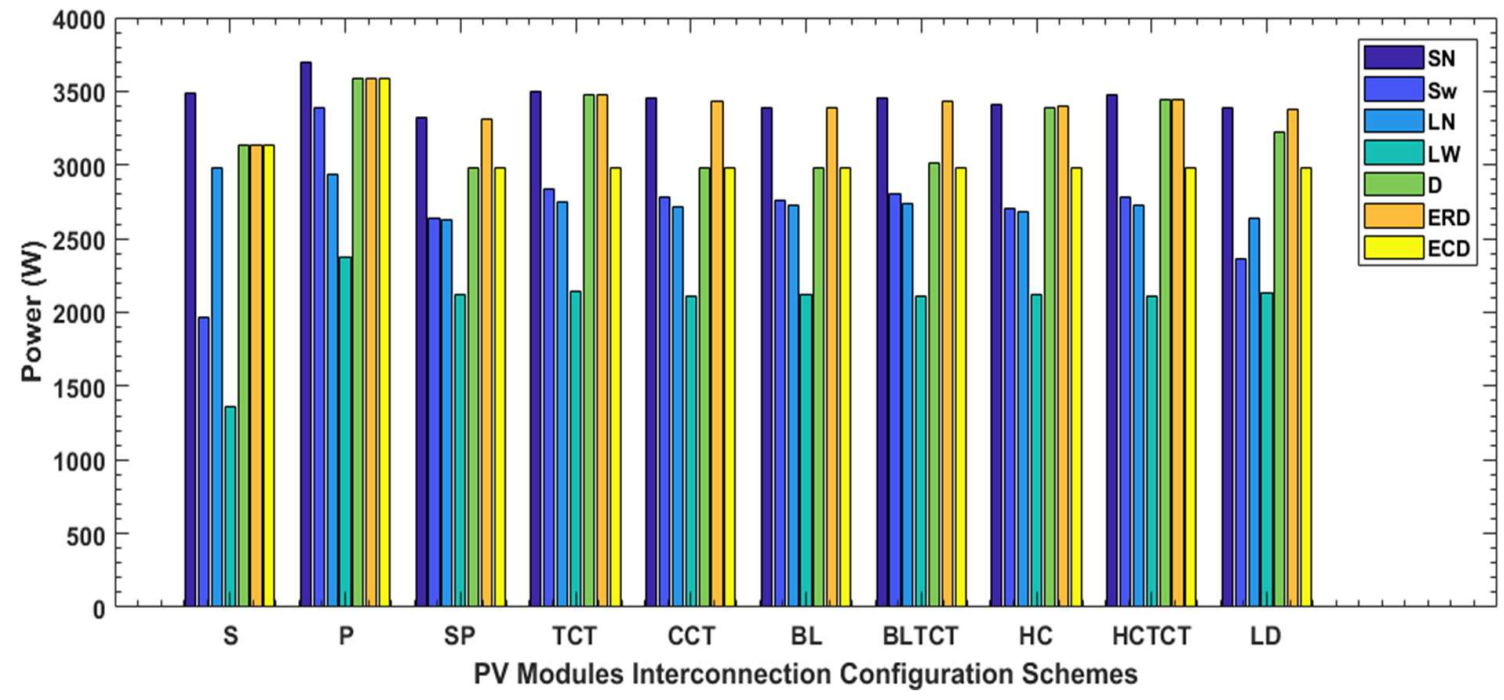

Fig.11. Comparative illustration of Maximum power generation of PV modules interconnection configuration schemes under partial shading patterns 


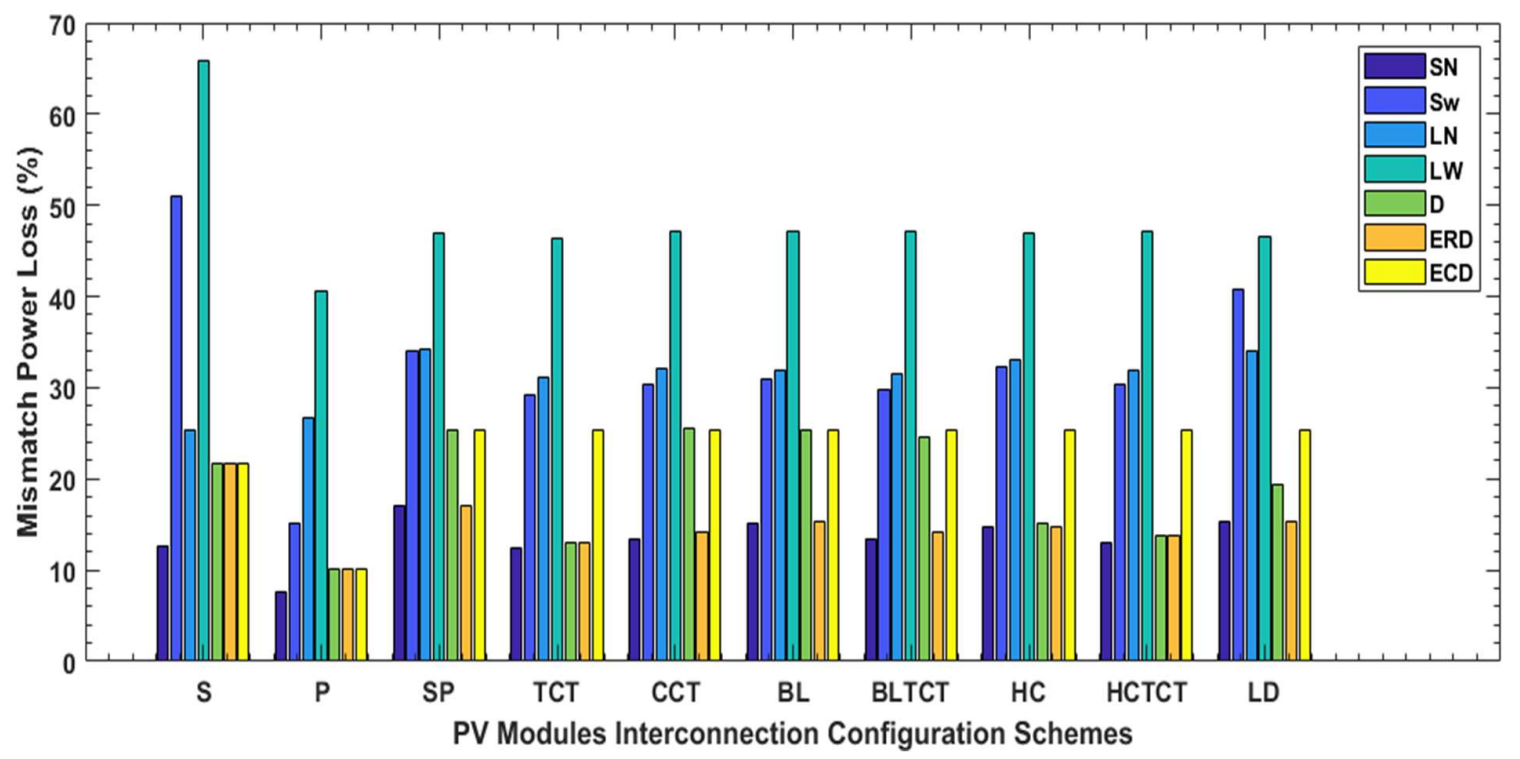

Fig.12. Comparative illustration of Mismatch power loss of PV modules interconnection configuration schemes under partial shading patterns

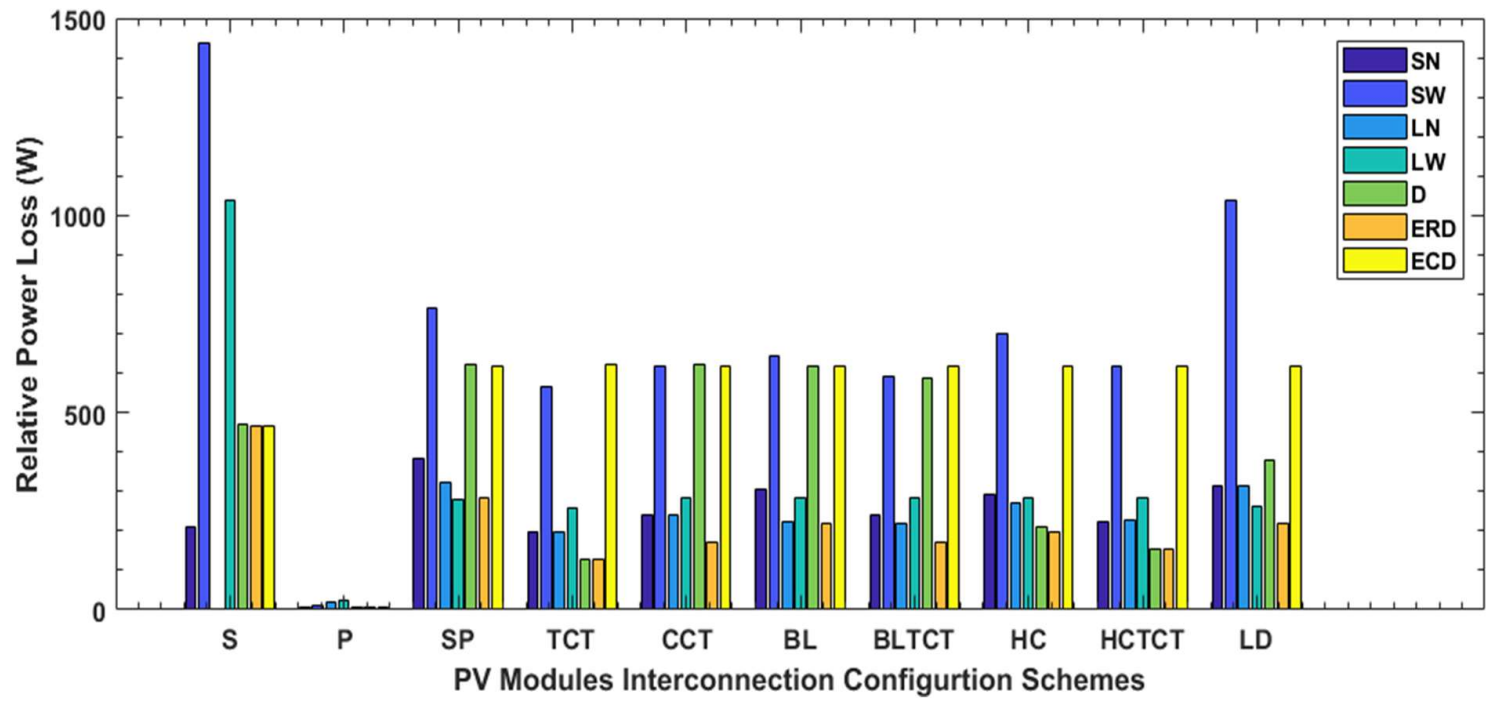

Fig.13. Comparative illustration of Relative power loss of PV modules interconnection configuration schemes under partial shading patterns

\section{$7 \quad$ PV Array Configurations Output Voltage and Current Expressions}

The mathematical expressions for the output voltage, current and power of the PV modules interconnection configuration schemes has been enlisted in Table 4. The expressions can be obtained on the same patterns as discussed in section 5.

Table 4. Different Array topologies Output Voltage, Current and the respective Power expressions

\begin{tabular}{|c|c|c|c|}
\hline Topology & $\begin{array}{c}\text { Array output voltage } \\
(\boldsymbol{V})\end{array}$ & $\begin{array}{c}\text { Array Output current } \\
(\mathrm{A})\end{array}$ & $\begin{array}{c}\text { Array output power } \\
(\mathbf{W})\end{array}$ \\
\hline $\mathrm{S}$ & $\begin{array}{l}\mathrm{V}_{\mathrm{o}}=\sum_{p=1}^{16} V_{\mathrm{p}}=16 \mathrm{~V}_{\mathrm{p}} \\
\mathrm{p}=\text { module voltage in a PV string }\end{array}$ & $\begin{array}{l}I_{0}=I_{q} \\
q=\text { module current in a PV string }\end{array}$ & $\mathrm{P}_{\mathrm{o}}=16 \times \mathrm{V}_{\mathrm{p}} \times \mathrm{I}_{\mathrm{q}}$ \\
\hline$P$ & $\begin{array}{l}\mathrm{V}_{\mathrm{o}}=\mathrm{Vp} \\
\mathrm{p}=\text { module voltage in a PV string }\end{array}$ & $\begin{array}{l}\mathrm{I}_{0}=\sum_{q=1}^{16} I_{\mathrm{q}}=16 \mathrm{I}_{\mathrm{q}} \\
\mathrm{q}=\text { module current in a PV string }\end{array}$ & $P_{o}=16 \times V_{p} \times I_{q}$ \\
\hline SP & $\begin{array}{l}\mathrm{V}_{\mathrm{o}}=\sum_{p=1}^{4} V_{\mathrm{p}}=4 \mathrm{~V}_{\mathrm{p}} \\
\mathrm{p}=\text { module voltage in a PV string }\end{array}$ & $\begin{array}{l}\mathrm{I}_{\mathrm{o}}=\mathrm{I}_{1}+\mathrm{I}_{5}+\mathrm{I}_{9}+\mathrm{I}_{13}=4 \mathrm{I}_{\mathrm{q}} \\
\mathrm{q}=\text { individual PV string current }\end{array}$ & $P_{o}=16 \times V_{p} \times I_{q}$ \\
\hline TCT & $\begin{array}{l}\mathrm{V}_{\mathrm{o}}=\mathrm{V}_{\mathrm{r} 1}+\mathrm{V}_{\mathrm{r} 2} \mathrm{~V}_{\mathrm{r} 3}+\mathrm{V}_{\mathrm{r} 4}=4 \mathrm{~V}_{\mathrm{r}} \\
\mathrm{r}=\text { individual PV row voltage }\end{array}$ & $\begin{array}{l}\mathrm{I}_{\mathrm{o}}=\mathrm{I}_{\mathrm{q} 1}+\mathrm{I}_{\mathrm{q} 5}+\mathrm{I}_{\mathrm{q} 9}+\mathrm{I}_{\mathrm{q} 13}=4 \mathrm{I}_{\mathrm{q}} \\
\mathrm{q}=\text { individual PV string current }\end{array}$ & $P_{o}=16 \times V_{r} \times I_{q}$ \\
\hline СCT & $\begin{array}{l}\mathrm{V}_{\mathrm{o}}=\sum_{p=1}^{4} V_{\mathrm{p}}=4 \mathrm{~V}_{\mathrm{p}} \\
\mathrm{p}=\text { module voltage in a PV string }\end{array}$ & $\begin{array}{l}\mathrm{I}_{\mathrm{o}}=\mathrm{I}_{1}+\mathrm{I}_{5}+\mathrm{I}_{9}+\mathrm{I}_{13}=4 \mathrm{I}_{\mathrm{q}} \\
\mathrm{q}=\mathrm{PV} \text { string current }\end{array}$ & $P_{o}=16 \times V_{p} \times I_{q}$ \\
\hline BL & $\begin{array}{l}\mathrm{V}_{\mathrm{o}}=\sum_{p=1}^{4} V_{\mathrm{p}}=4 \mathrm{~V}_{\mathrm{p}} \\
\mathrm{p}=\text { module voltage in a PV string }\end{array}$ & $\begin{array}{l}\mathrm{I}_{\mathrm{o}}=\mathrm{I}_{1}+\mathrm{I}_{5}+\mathrm{I}_{9}+\mathrm{I}_{13}=4 \mathrm{I}_{\mathrm{q}} \\
\mathrm{q}=\mathrm{PV} \text { string current }\end{array}$ & $P_{o}=16 \times V_{p} \times I_{q}$ \\
\hline BLTCT & $\begin{array}{l}\mathrm{V}_{\mathrm{o}}=\sum_{p=1}^{4} V_{\mathrm{p}}=4 \mathrm{~V}_{\mathrm{p}} \\
\mathrm{p}=\text { module voltage in a PV string }\end{array}$ & $\begin{array}{l}I_{0}=I_{1}+I_{5}+I_{9}+I_{13}=4 I_{q} \\
q=P V \text { string current }\end{array}$ & $P_{o}=16 \times V_{p} \times I_{q}$ \\
\hline $\mathrm{HC}$ & $\begin{array}{l}\mathrm{V}_{\mathrm{o}}=\sum_{p=1}^{4} V_{\mathrm{p}}=4 \mathrm{~V}_{\mathrm{p}} \\
\mathrm{p}=\text { module voltage in a PV string }\end{array}$ & $\begin{array}{l}\mathrm{I}_{0}=\mathrm{I}_{1}+\mathrm{I}_{5}+\mathrm{I}_{9}+\mathrm{I}_{13}=4 \mathrm{I}_{\mathrm{q}} \\
\mathrm{q}=\mathrm{PV} \text { string current }\end{array}$ & $P_{o}=16 \times V_{p} \times I_{q}$ \\
\hline НCTCT & $\begin{array}{l}\mathrm{V}_{\mathrm{o}}=\sum_{p=1}^{4} V_{\mathrm{p}}=4 \mathrm{~V}_{\mathrm{p}} \\
\mathrm{p}=\text { module voltage in a PV string }\end{array}$ & $\begin{array}{l}\mathrm{I}_{0}=\mathrm{I}_{1}+\mathrm{I}_{5}+\mathrm{I}_{9}+\mathrm{I}_{13}=4 \mathrm{I}_{\mathrm{q}} \\
\mathrm{q}=\mathrm{PV} \text { string current }\end{array}$ & $P_{o}=16 \times V_{p} \times I_{q}$ \\
\hline LD & $\begin{array}{l}\mathrm{V}_{\mathrm{o}}=\sum_{p=1}^{4} V_{\mathrm{p}}=4 \mathrm{~V}_{\mathrm{p}} \\
\mathrm{p}=\text { module voltage in a PV string }\end{array}$ & $\begin{array}{l}I_{0}=I_{1}+I_{5}+I_{9}+I_{13}=4 I_{q} \\
q=P V \text { string current }\end{array}$ & $P_{o}=16 \times V_{p} \times I_{q}$ \\
\hline
\end{tabular}




\section{Conclusion}

A comparative performance analysis of the PV modules interconnection configuration schemes including S, P, SP, TCT, CCT, BL, BLTCT, HC, HCTCT, LD under STC, and PSCs is discussed in the paper. The parameters including $V_{m p}, I_{m p}, P_{m p} V_{o c}, I_{s c}, \Delta \mathrm{P}_{\mathrm{ml}}, P_{r l}, \mathrm{FF}, \mathrm{NOP}, \mathrm{GMPP}, \mathrm{LMPP}$ are extracted for each of the array topologies. The paper provides a comprehensive study of the PV array topologies under various PSCs in comparison to the work investigated earlier and in the literature review. Accurate mathematical modeling for HCTCT configuration under ERD and ECD partial shading pattern has been performed and simulation results verified the numerical analysis. In addition, passing clouds have been simulated and shading variants have been obtained based on mathematical modeling. The paper investigates that $P$ configuration yield the maximum power output with minimum mismatch power losses and relative power losses but the contribution of high current limits its use for practical PV applications. The greater NOPs in S array configuration limits its use for practical application as it is more prone to mismatch power losses and on average, the relative power losses are even greater than $580 \mathrm{~W}$. The descending trend for PV array configurations in extracting $P_{m p}$ under different shading patterns is summarized below;

SN Shading Pattern

$\mathrm{P}>\mathrm{TCT}>\mathrm{S}>\mathrm{HCTCT}>\mathrm{CCT}=\mathrm{BLTCT}>\mathrm{HC}>\mathrm{BL}>\mathrm{LD}>\mathrm{SP}$

SW Shading Pattern

$\mathrm{P}>\mathrm{TCT}>\mathrm{BLTCT}>\mathrm{CCT}=\mathrm{HCTCT}>\mathrm{BL}>\mathrm{HC}>\mathrm{SP}>\mathrm{LD}>\mathrm{S}$

LN Shading Pattern

S $>$ P $>$ TCT $>$ BLTCT $>$ BL $>$ HCTCT $>$ HC $>$ LD $>$ CCT $>$ SP

LW Shading Pattern

$\mathrm{P}>\mathrm{TCT}>\mathrm{LD}>\mathrm{BL}>\mathrm{SP}>\mathrm{HC}>\mathrm{BL}>\mathrm{CCT}=\mathrm{HCTCT}=\mathrm{BLTCT}>\mathrm{SP}$

D Shading Pattern

$\mathrm{P}>\mathrm{TCT}>\mathrm{HCTCT}>\mathrm{HC}>\mathrm{S}>\mathrm{LD}>\mathrm{BLTCT}>\mathrm{BL}>\mathrm{SP}>\mathrm{CCT}$

ERD Shading Pattern

$\mathrm{P}>\mathrm{TCT}>\mathrm{HCTCT}>\mathrm{CCT}=\mathrm{HCTCT}>\mathrm{S}>\mathrm{HC}>\mathrm{BL}>\mathrm{LD}>\mathrm{SP}>\mathrm{S}$

ERD Shading Pattern

$\mathrm{P}>\mathrm{BLTCT}>\mathrm{SP}=\mathrm{TCT}=\mathrm{CCT}=\mathrm{BL}=\mathrm{HC}=\mathrm{HCTCT}=\mathrm{LD}>\mathrm{S}$

The mismatch power loss trend is a vice versa of maximum power generation trend. It can be observed that TCT array configuration yielded more power output and minimum mismatch power losses as well as relative power losses among all configurations after P configuration. The more number of series electrical connections makes it less economical. Besides these, the hybrid PV configurations including BLTCT and HCTCT yielded power output quite closer to the TCT configuration in all shading patterns and has a minimum $\Delta \mathrm{P}_{\mathrm{ml}}$ and $P_{r l}$ and making them superior over conventional array topologies. In addition, the comprehensive study regarding PV array topologies investigated in the paper can become a satisfactory source in the selection of optimal PV array topology taking into account the impacts of PSCs for a specific site.

\section{Author Contribution}

All authors contributed equally to this work.

\section{Declaration of Interest}

The authors declare no competing interest.

\section{Funding}

This research did not receive any specific grant from funding agencies in the public, commercial, or not-for-profit sectors.

\section{References}

[1] T. Hargreaves, L. Middlemiss, The importance of social relations in shaping energy demand, Nat. Energy. 5 (2020). https://doi.org/10.1038/s41560-020-0553-5.

[2] K. Moustakas, M. Loizidou, M. Rehan, A.S. Nizami, A review of recent developments in renewable and sustainable energy systems: Key challenges and future perspective, Renew. Sustain. Energy Rev. 119 (2020). https://doi.org/10.1016/j.rser.2019.109418.

[3] J.C. de Oliveira Matias, R. Godina, E. Pouresmaeil, Sustainable energy systems: Optimization and efficiency, Appl. Sci. 10 (2020). https://doi.org/10.3390/app10124405.

[4] Yousuf, M.H.; Saeed, F.; Tauqeer, H.A. Numerical Investigation of Cu2O as Hole Transport Layer for High-Efficiency CIGS Solar Cell. Preprints 2021, 2021100326 (doi: 10.20944/preprints202110.0326.v1).

[5] P.A. Fokaides, R. Apanaviciene, J. Černeckiene, A. Jurelionis, E. Klumbyte, V. Kriauciunaite-Neklejonoviene, D. Pupeikis, D. Rekus, J. Sadauskiene, L. Seduikyte, L. Stasiuliene, J. Vaiciunas, R. Valancius, T. Ždankus, Research challenges and advancements in the field of sustainable energy technologies in the built environment, Sustain. 12 (2020). https://doi.org/10.3390/su12208417. A.S. Abdelrazik, K.H. Tan, N. Aslfattahi, A. Arifutzzaman, R. Saidur, F.A. Al-Sulaiman, Optical, stability and energy performance of water-based MXene nanofluids in hybrid PV/thermal solar systems, Sol. Energy. 204 (2020). https://doi.org/10.1016/j.solener.2020.04.063.

[7] T. Hooper, A. Armstrong, B. Vlaswinkel, Environmental impacts and benefits of marine floating solar, Sol. Energy. 219 (2021). https://doi.org/10.1016/j.solener.2020.10.010.

[8] IEA (2020), Renewables 2020, IEA, Paris, (n.d.). https://www.iea.org/reports/renewables-2020.

[9] V.R. Vakacharla, K. Gnana, P. Xuewei, B.L. Narasimaharaju, M. Bhukya, A. Banerjee, R. Sharma, A.K. Rathore, State-of-the-art power electronics systems for solar-to-grid 
integration, Sol. Energy. 210 (2020). https://doi.org/10.1016/j.solener.2020.06.105.

[10] L. Al-Ghussain, R. Samu, O. Taylan, M. Fahrioglu, Sizing renewable energy systems with energy storage systems in microgrids for maximum cost-efficient utilization of renewable energy resources, Sustain. Cities Soc. 55 (2020). https://doi.org/10.1016/j.scs.2020.102059.

[11] E. Kabalc1, Review on novel single-phase grid-connected solar inverters: Circuits and control methods, Sol. Energy. 198 (2020). https://doi.org/10.1016/j.solener.2020.01.063.

[12] P.K. Bonthagorla, S. Mikkili, Performance analysis of PV array configurations ( SP , BL, HC and TT ) to enhance maximum power under non-uniform shading conditions, Eng. Reports. 2 (2020). https://doi.org/10.1002/eng2.12214.

[13] A.A. Desai, S. Mikkili, Modelling and analysis of PV configurations (alternate TCT-BL, total cross tied, series, series parallel, bridge linked and honey comb) to extract maximum power under partial shading conditions, CSEE J. Power Energy Syst. PP (2019). https://doi.org/10.17775/CSEEJPES.2020.00900.

[14] C. Saiprakash, A. Mohapatra, B. Nayak, S.R. Ghatak, Analysis of partial shading effect on energy output of different solar PV array configurations, Mater. Today Proc. 39 (2021). https://doi.org/10.1016/j.matpr.2020.08.307

[15] D.P. Winston, S. Kumaravel, B.P. Kumar, S. Devakirubakaran, Performance improvement of solar PV array topologies during various partial shading conditions, Sol. Energy. 196 (2020). https://doi.org/10.1016/j.solener.2019.12.007.

[16] Manjunath, H.N. Suresh, S. Rajanna, Reduction of mislead power and mismatch power loss under partial shading conditions using novel square matrix shade dispersion technique, Sol. Energy. 207 (2020). https://doi.org/10.1016/j.solener.2020.07.036.

[17] S. Gallardo-Saavedra, L. Hernández-Callejo, M.D.C. Alonso-García, J. Muñoz-Cruzado-alba, J. Ballestín-Fuertes, Infrared thermography for the detection and characterization of photovoltaic defects: Comparison between illumination and dark conditions, Sensors (Switzerland). 20 (2020). https://doi.org/10.3390/s20164395.

[18] L. Garcia-Gutierrez, M. Bressan, A. Sferlazza, F. Jimenez, S. De-Las-Heras, C. Alonso, Development of a high granularity photovoltaic model that considers complex nonuniform shadow conditions and different cell temperatures, in: Lect. Notes Electr. Eng., 2020. https://doi.org/10.1007/978-3-030-56970-9_4.

[19] A. Ghosh, Soiling Losses: A Barrier for India's Energy Security Dependency from Photovoltaic Power, Challenges. 11 (2020). https://doi.org/10.3390/challe11010009.

[20] M.H. Zafar, T. Al-Shahrani, N.M. Khan, A.F. Mirza, M. Mansoor, M.U. Qadir, M.I. Khan, R.A. Naqvi, Group teaching optimization algorithm based mppt control of pv systems under partial shading and complex partial shading, Electron. 9 (2020). https://doi.org/10.3390/electronics9111962.

[21] R.G. Vieira, F.M.U. de Araújo, M. Dhimish, M.I.S. Guerra, A comprehensive review on bypass diode application on photovoltaic modules, Energies. 13 (2020). https://doi.org/10.3390/en13102472.

[22] N. Agrawal, B. Bora, A. Kapoor, Experimental investigations of fault tolerance due to shading in photovoltaic modules with different interconnected solar cell networks, Sol. Energy. 211 (2020). https://doi.org/10.1016/j.solener.2020.10.060.

[23] R.K. Pachauri, O.P. Mahela, A. Sharma, J. Bai, Y.K. Chauhan, B. Khan, H.H. Alhelou, Impact of partial shading on various PV array configurations and different modeling approaches: A comprehensive review, IEEE Access. 8 (2020). https://doi.org/10.1109/ACCESS.2020.3028473.

[24] G. Meerimatha, B.L. Rao, Novel reconfiguration approach to reduce line losses of the photovoltaic array under various shading conditions, Energy. 196 (2020). https://doi.org/10.1016/j.energy.2020.117120.

[25] Z. Wang, N. Zhou, L. Gong, M. Jiang, Quantitative estimation of mismatch losses in photovoltaic arrays under partial shading conditions, Optik (Stuttg). 203 (2020). https://doi.org/10.1016/j.ijleo.2019.163950.

[26] M.C. Alonso-García, J.M. Ruiz, W. Herrmann, Computer simulation of shading effects in photovoltaic arrays, Renew. Energy. 31 (2006). https://doi.org/10.1016/j.renene.2005.09.030.

[27] D.D. Nguyen, B. Lehman, Modeling and simulation of solar PV arrays under changing illumination conditions, in: Proc. IEEE Work. Comput. Power Electron. COMPEL, 2006. https://doi.org/10.1109/COMPEL.2006.305629.

[28] E. Karatepe, M. Boztepe, M. Çolak, Development of a suitable model for characterizing photovoltaic arrays with shaded solar cells, Sol. Energy. 81 (2007). https://doi.org/10.1016/j.solener.2006.12.001

[29] V. Di Dio, D. La Cascia, R. Miceli, C. Rando, A mathematical model to determine the electrical energy production in photovoltaic fields under mismatch effect, in: 2009 Int. Conf. Clean Electr. Power, ICCEP 2009, 2009. https://doi.org/10.1109/ICCEP.2009.5212083.

[30] R. Ramaprabha, B.L. Mathur, A comprehensive review and analysis of solar photovoltaic array configurations under partial shaded conditions, Int. J. Photoenergy. 2012 (2012). https://doi.org/10.1155/2012/120214

[31] Z. Salam, M.Z. Ramli, A simple circuit to improve the power yield of PV array during partial shading, in: 2012 IEEE Energy Convers. Congr. Expo. ECCE 2012, 2012. https://doi.org/10.1109/ECCE.2012.6342619.

[32] F. Belhachat, C. Larbes, Modeling, analysis and comparison of solar photovoltaic array configurations under partial shading conditions, Sol. Energy. 120 (2015). https://doi.org/10.1016/j.solener.2015.07.039

[33] S. Mohammadnejad, A. Khalafi, S.M. Ahmadi, Mathematical analysis of total-cross-tied photovoltaic array under partial shading condition and its comparison with other configurations, Sol. Energy. 133 (2016). https://doi.org/10.1016/j.solener.2016.03.058

[34] S. Vijayalekshmy, G.R. Bindu, S.R. Iyer, Performance Improvement of Partially Shaded Photovoltaic Arrays under Moving Shadow Conditions through Shade Dispersion, J. Inst. Eng. Ser. B. 97 (2016). https://doi.org/10.1007/s40031-015-0199-z.

[35] S.R. Pendem, S. Mikkili, Modeling, simulation and performance analysis of solar PV array configurations (Series, Series-Parallel and Honey-Comb) to extract maximum power under Partial Shading Conditions, Energy Reports. 4 (2018). https://doi.org/10.1016/j.egyr.2018.03.003.

[36] O. Bingöl, B. Özkaya, Analysis and comparison of different PV array configurations under partial shading conditions, Sol. Energy. 160 (2018). https://doi.org/10.1016/j.solener.2017.12.004

[37] S.R. Pendem, S. Mikkili, Modelling and performance assessment of PV array topologies under partial shading conditions to mitigate the mismatching power losses, Sol. Energy. 160 (2018). https://doi.org/10.1016/j.solener.2017.12.010.

[38] M. Premkumar, U. Subramaniam, T.S. Babu, R.M. Elavarasan, L. Mihet-Popa, Evaluation of mathematical model to characterize the performance of conventional and hybrid PV array topologies under static and dynamic shading patterns, Energies. 13 (2020). https://doi.org/10.3390/en13123216.

[39] S.S. Reddy, C. Yammani, A novel Magic-Square puzzle based one-time PV reconfiguration technique to mitigate mismatch power loss under various partial shading conditions, Optik (Stuttg). 222 (2020). https://doi.org/10.1016/j.ijleo.2020.165289.

[40] C. Huang, L. Wang, H. Long, X. Luo, J.H. Wang, A hybrid global maximum power point tracking method for photovoltaic arrays under partial shading conditions, Optik (Stuttg). 180 (2019). https://doi.org/10.1016/j.ijleo.2018.11.158. 
[41] Z. Wang, N. Zhou, L. Gong, M. Jiang, Quantitative estimation of mismatch losses in photovoltaic arrays under partial shading conditions, Optik (Stuttg). 203 (2020). https://doi.org/10.1016/j.ijleo.2019.163950.

[42] Z. Yang, K. Liao, J. Chen, L. Xia, X. Luo, Output performance analysis and power optimization of different configurations half-cell modules under partial shading, Optik (Stuttg). 232 (2021). https://doi.org/10.1016/j.ijleo.2021.166499

[43] W. Kreft, M. Filipowicz, M. Żołądek, Reduction of electrical power loss in a photovoltaic chain in conditions of partial shading, Optik (Stuttg). 202 (2020). https://doi.org/10.1016/j.ijleo.2019.163559.

[44] R. Pachauri, R. Singh, A. Gehlot, R. Samakaria, and S. Choudhury, "Experimental analysis to extract maximum power from PV array reconfiguration under partial shading conditions," Eng. Sci. Technol. an Int. J., vol. 22, no. 1, 2019, doi: 10.1016/j.jestch.2017.11.013.

[45] G. M. Madhu, C. Vyjayanthi, and C. N. Modi, "Investigation on Effect of Irradiance Change in Maximum Power Extraction from PV Array Interconnection Schemes during Partial Shading Conditions," IEEE Access, vol. 9, 2021, doi: 10.1109/ACCESS.2021.3095354. 
